\title{
BIOCHAR REPLACES PEAT IN HORTICULTURE: ENVIRONMENTAL IMPACT ASSESSMENT OF COMBINED BIOCHAR \& BIOENERGY PRODUCTION
}

\author{
Lydia Fryda ${ }^{1, *}$, Rianne Visser ${ }^{1}$ and Jannick Schmidt ${ }^{2}$ \\ ${ }^{1}$ Energy Research Centre of the Netherlands, ECN, part of TNO, P.O. Box 1, 1755 ZG Petten, The Netherlands \\ 22.-0 LCA consultants, Denmark
}

Article Info:
Received:
4 October 2018
Revised:
3 December 2018
Accepted:
19 December 2018
Available online:
31 March 2019
Keywords:
Biochar
Peat
LCA
Bioenergy
Gasification
Substrate
Horticulture

Received:

4 October 2018

Accepted:

19 December 2018

31 March 2019

Keywords:

Biochar

LCA

\begin{abstract}
Horticulture in temperate climate zones is energy intensive and the use of peat as the main ingredient in substrates releases additional GHG emissions during mining and processing. This paper evaluates the environmental impact of the co-production and application of bioenergy and biochar using agricultural and woody feedstock to replace natural gas and peat in horticulture by means of a life cycle analysis (LCA), including the timing of $\mathrm{CO}_{2}$ release and uptake, the decay of peat and biochar and the carbon stability of biochar and peat. Lab-scale data on biochar carbon recalcitrance compared to peat ( $80 \%$ vs. $40 \%$ respectively) indicate that spent biochar-based substrates in soil are a carbon storage tool. The combination of bioenergy replacing fossil energy, biochar replacing peat in substrate and long term storage of the spent biochar in soil, contribute to GHG reductions.
\end{abstract}

\section{INTRODUCTION}

\subsection{Environmental aspects of current horticultural practice}

The impetus to apply climate control measures and reduce greenhouse gas (GHG) emissions has forced the world community to be inventive in using renewable energy sources and bio-based products. The co-production of bioenergy and biochar from biogenic feedstock is a potential measure that can contribute towards gaining independence from fossil resources.

Horticulture in temperate climate zones is energy intensive and almost entirely relies on fossil-based natural gas. In the Netherlands, the heating of greenhouses produces $4 \%$ of the national $\mathrm{CO}_{2}$ emissions and is thus a sector where a significant reduction in fossil-fuel use can be achieved (Verhagen et al., 2009). However, the use of biomass-based fuels to replace fossil fuels and the associated reduction in $\mathrm{GHG}$ emissions is still under debate (Cherubini et al., 2009, Cherubini and Strømman, 2011). Research into the processes associated with preparing and transporting biomass fuel and the timing of $\mathrm{CO}_{2}$ uptake by trees have not only brought more insight into the net- $\mathrm{CO}_{2}$ release from bioenergy but also more controversy around the use of biomass for energy. The co-production of bioenergy and biochar offers additional benefits and a further reduction in GHG once biochar is used for peat replacement and as carbon storage in open fields after its use in horticulture. To evaluate whether the co-production of bioenergy with biochar as a peat replacement and carbon-storage solution is a better alternative to the current practice, an LCA study is performed to substantiate the claim.

This LCA study thoroughly characterises the environmental impact of the proposed system of co-producing bioenergy and biochar, including the use of biochar as peat replacement and carbon storage, and compares it with the current practice. Special focus is paid to the GHG emissions aspect of the system's environmental burden and whether the new proposed system does indeed lead to a significant reduction of GHG.

A proper description of the current situation is necessary to explain the boundaries of the study. This paper considers the current practice in modern greenhouses in the Netherlands with respect to energy consumption, the application of $\mathrm{CO}_{2}$ as a fertiliser and the use of peat as the main ingredient of substrates. Then the state of the art in peat replacement is discussed as well as the technical background of the conversion technology that forms the heart of the LCA functional unit.

Modern greenhouses consume fossil-based natural 
gas for heating and lighting the space as well as for the generation of $\mathrm{CO}_{2}$ to accelerate plant growth. In addition, they use Sphagnum peat in soilless substrates because of its unique ability to hold and release water. However, the extraction of peat leads to the disturbance of peatlands. Through draining and aeration of the bogs, labile carbon is exposed to an aerobic environment, which results in rapid emissions of $\mathrm{CO}_{2}, \mathrm{CH}_{4}$ and $\mathrm{N}_{2} \mathrm{O}$ (Karki, 2018). The European Commission promotes the replacement of peat with more sustainable materials through various funding schemes (e.g., FERTIPLUS [FP7], HortiBlue-C [Interreg]) as it has been recognised that peat is a non-renewable resource, and its mining is a source of GHG emissions (Kern et al., 2017).

Sphagnum peat moss improves the physical properties of growing media, such as the medium's bulk density, water-holding capacity (the volume percentage of water retained after a saturated growing medium is allowed to drain) and air porosity (the volume of pore space occupied by air after a saturated growing medium is allowed to drain; Paulis, 2017; Chalker-Scott, 2014). In addition, peat moss assists the nutrient-holding and -exchange system, serves as an anchor point for a plant's roots and assists the root systems' respiration. Any alternative material replacing peat must exhibit the same properties in a growing medium and must be stable enough to avoid decaying during its use in a substrate mixture. Considerable research has been carried out in creating blends of peat with coconut fibre, perlite, rice hulls and barks as peat alternatives (Dispenza, 2016; Fascella, 2015). In recent years, biochar has gained attention as a (partial) substitute for peat moss.

Although research on the use of biochar as a peat replacement is not yet conclusive, the number of relevant publications is increasing very quickly. In the national research project Enerchar, conducted in cooperation with Wageningen University, some very successful pot trials have been performed that replaced up to $50 \%$ of peat (Blok et al. 2017). The works of Steiner and Harttung, (2014), Vaughn et al. (2015) and Kern et al. (2017) support the notion that biochar can replace peat due to its high porosity, low density and high cation-exchange capacity. The use of biochar produced from agro- and woody residual feedstocks as a substrate for soilless plant production can provide growers with a cost-effective and environmentally responsible alternative to the currently used peat substrates (Blok et al., 2017). In a very recent work, Margenot et al. (2018) demonstrated that softwood biochar can be considered as a full replacement for peat in soil-free substrates at high rates (70\% total substrate volume) for marigold production. Since thermal technologies are still scaling up, commercial biochar is not readily available yet.

In addition to the reduced need for natural peat mining, the use of biochar after its use in horticulture can contribute to carbon capture and storage (CCS) when it is applied in open (agricultural) fields (Woolf et al., 2010). So far, biochar has not been considered as a CCS tool in the mitigation scenarios of the Intergovernmental Panel on Climate Change's (IPCC's) Fifth Assessment Report (IPCC, 2014a). However, more and more non-governmental organisations and governmental bodies have identified biochar as an option in future scenarios (van Vuuren et al., 2017). Schmidt et al. (2017) showed that pyrogenic CCS can be a negative-emission system with considerable carbon sequestration potential when the pyrolysis (carbon) co-products are used as bio-based materials, agronomic amendments and/ or geologic carbon storage (i.e. storing the carbon without it transitioning to $\mathrm{CO}_{2}$ for at least dozens or hundreds of years). To recognise the soil amendment of biochar as a CCS option, the stability of the carbon is key. Therefore, we paid special attention to this parameter and incorporated results from experiments into the LCA study as a novel contribution.

In the proposed new system, biochar is co-produced with bioenergy. Because this new technology and the application of biochar is at the heart of the LCA evaluation, some additional, relevant information is provided here.

\subsection{Description of the Enerchar co-production sys- tem}

The conversion of biomass residues to bioenergy and biochar requires technologies with flexibility to handle residues with fluctuating and challenging properties. Due to the high alkali content of some residues, a system converting biomass residues is best operated at relatively low temperatures $\left(<700^{\circ} \mathrm{C}\right)$ to avoid slagging and fouling in the thermal conversion installation. Low-temperature fluidised bed gasifiers (Fryda \& Visser, 2015) allow the valorisation of a range of biomass feedstock of variable compositions, including those with high alkali content and low melting temperature of the ash. In a fluidised bed gasifier (operating at temperatures below $700^{\circ} \mathrm{C}$ ), the volatile material of the biomass is used for energy generation while biochar (the non-converted feedstock) is harvested in the bottom of the installation. Special attention is paid to the separation of the gas phase and the carbon product in an early stage of the process to avoid any tar condensation on the biochar product. For the use of biochar in horticulture, the absence or minimal presence of tar is a quality requirement. Any tars in the gas phase are burned by secondary air, and energy is generated via a traditional steam system. The following block diagram in Figure 1 presents the Enerchar system (energy and biochar), where biomass is gasified at a relatively low temperature to produce heat and energy (electricity) from the volatile compounds in the biomass, and biochar is produced from the recalcitrant carbon fraction.

In addition to replacing peat, this study explores the CCS potential of biochar in soil after its lifetime in the greenhouse. The study includes the timing of $\mathrm{CO}_{2}$ emissions from feedstocks, including the growth and decay rates of various types of biomass, peat and biochar. The three main reductions in environmental burden achieved by the Enerchar system are as follows: (i) avoiding the impact of fossil-fuel use by substitution with bio-syngas (the gas product from bioenergy production); (ii) avoiding the impact of peat extraction and use, which is replaced by biochar production and use; and (iii) avoiding the production of $\mathrm{CO}_{2}$ by the final use of stable biochar in soil as an end-of-of-life option instead of fast-decaying peat. All three streams are incorporated in the LCA study. The application 


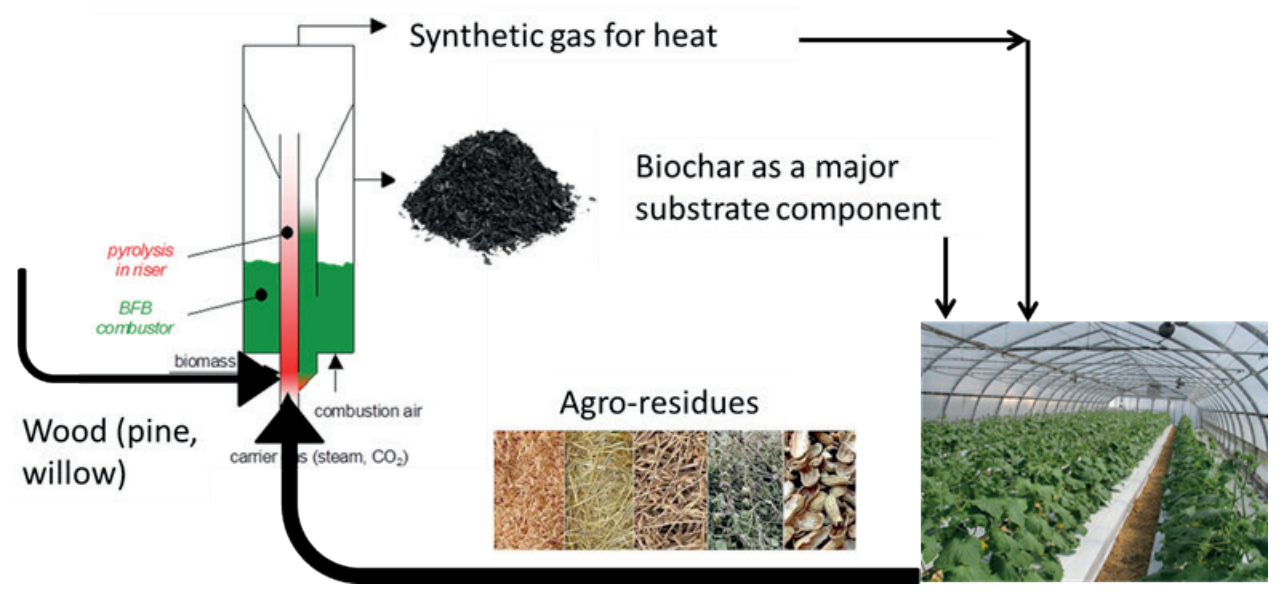

FIGURE 1: Block diagram of the proposed integrated bioenergy and biochar system (Enerchar project).

of biochar as a fertiliser or soil improver is not considered and neither are any alternative uses of biochar, such as using biochar to replace coal or charcoal pellets.

Although the technology's development is only in its pilot stage phase, it is still useful to carry out an LCA analysis because process improvements and optimisation can still be applied at this stage rather than at commercialisation. The LCA is performed in a comparative rather than an absolute way, which means that within a specified set of criteria, one product or process is compared to another or to a reference.

\subsection{List of abbreviations}

CEC Cation exchange capacity

(BE)CCS Bioenergy with carbon capture and storage

$\mathrm{CH}_{4} \quad$ Methane

$\mathrm{CO}_{2-\mathrm{eq}} \quad$ Carbon dioxide equivalent

$\mathrm{CF}^{2-e q} \quad$ Characterisation factor

EBC European biochar certificate

EC Electrical conductivity

ECN Energy Research Centre of the Netherlands

GHG Greenhouse gas

IBI International Biochar Initiative

IPCC Intergovernmental Panel on Climate Change

$\mathrm{K} \quad$ Potassium

LCA Life cycle analysis

LCI Life cycle inventory

LUC Land-use change

$\mathrm{mS} \quad$ Millisiemens

Mt Megatons

$\mathrm{N} \quad$ Nitrogen

$\mathrm{N}_{0} \quad$ Initial carbon quantity

$\mathrm{N}_{2} \mathrm{O} \quad$ Nitrous oxide

NPP Net primary production

OM Organic matter

P Phosphorus

PAH Polycyclic aromatic hydrocarbon

SD Standard deviation

$\mathrm{T} \quad$ Rotation time (years)

$t_{1 / 2} \quad$ Half-life

WHC Water-holding capacity

\section{MATERIALS AND METHODS}

\subsection{Experimental data relevant for the LCA study}

The ecoinvent database and others are valuable sources of inputs for an LCA inventory, but, if available, it is important to include laboratory test results that define the process in more detail. In that respect, it is important to elaborate on the stability of biochar carbon to gain confidence in its sequestration capacity. A very recent review published by Leng et al. (2019) presents and assesses comprehensive, detailed and up-to-date information on the development methods studied for biochar stability. Among the proposed methods, $\mathrm{H}_{2} \mathrm{O}_{2}$ and heat-assisted oxidation (also called the Edinburgh stability tool) is listed among the most promising proxies to indicate biochar stability. The Edinburgh stability tool was developed by Cross and Sohi (2013) as an accelerated ageing method that seeks to reflect the oxidative degradation (ageing) of biochar in soil. Although the method presented in that work still needs wider acceptance and use by a broader biochar producer and the user public, it is the only current lab-scale method that provides an analogue for long-term carbon stability in a short period of time. A set of oxidation tests were carried out at ECN, part of TNO (Energy Research Centre of the Netherlands, part of the Netherlands Organisation for Applied Scientific Research), following the methodology suggested by Cross and Sohi (2013). A set of materials, including biochar, graphite, active carbon and fresh biomass samples, were milled to powder and dried overnight at $80^{\circ} \mathrm{C}$. A one-gram ( $1 \mathrm{~g}$ milled) sample of each biochar was weighted into a glass test tube, and then $0.1 \mathrm{~mol} \mathrm{H}_{2} \mathrm{O}_{2}$ in a solution of $70 \mathrm{ml}$ deionized water was added to the test tube while agitating the test tube to ensure all biochar remained in suspension. The tubes were heated to $80^{\circ} \mathrm{C}$ in a thermal oxidation step, during which they were agitated continuously. After 2 days of heating, the solution evaporated, and the tubes were placed into an oven at $105^{\circ} \mathrm{C}$. After cooling in a desiccator, the tubes were reweighed to determine mass loss. The results, presented in Section 3.1, were used in the carbon stability calculations during the inventory section of the LCA study.

The mass and energy values relevant to the Enerchar system have been obtained from the nonconfidential data 
from the project report on Enerchar and are presented in the life cycle inventory Section 2.2.3.

\subsection{Life cycle analysis of the Enerchar technology}

The software SimaPro v.8.5 was used for the LCA study. A consequential LCA was conducted, meaning that the activities related to production (of the main or reference product) are considered in such a way that any change in the demand for the main product will affect these activities too (Consequential LCA, n.d.). The goal and scope are described in Section 2.2.1. The system boundary and functional unit are then described in detail in Section 2.2.2. This section presents the Enerchar system in detail to explain the assumptions that are crucial for this LCA study and to help in understanding the functional unit. The life cycle inventory $(\mathrm{LCl})$ is described in Section 2.2.3. Material and process streams are included in the system (e.g., natural resources, auxiliary energy, chemicals, emissions to air, effluents to soil and water). At the end of this phase, the $\mathrm{LCl}$ is complete, which SimaPro converts to a list containing hundreds of 'elementary flows'-that is, emissions or extractions to and from the environment that occur during the system's production and the materials and processes that link to it. The interpretation of this long list of material flows needs to be done in a standardised manner regulated by the International Organization for Standardization (ISO) standards for LCA studies.

Following the $\mathrm{LCl}$, the impact of the proposed system on the environment is assessed. The method for this is described in detail in Section 2.2.4. This phase is the life cycle impact assessment (LCIA), which aims at understanding and evaluating the magnitude and significance of the potential impacts of a system on the environment. This last stage is further sub-divided into classification, characterisation and weighting.

2.2.1 Goal and scope of the study: Limitations and assumptions regarding the Enerchar system versus the current state of the art

The goal of this LCA study is (1) to evaluate the environmental impact of the co-production of syngas and biochar and (2) to compare the co-production, use and end-of-life stage of syngas and biochar with their currently applied reference processes, which are the use of natural gas for greenhouse heating and the use of peat in substrates. The study identifies improvement options and environmental 'hot spots' (i.e., major sources of impact) and follows the production of biochar and syngas from residual wood collected by municipalities and their application in a greenhouse. Then, the study estimates the impacts avoided by replacing peat with biochar and natural gas-based heat with syngas-based heat. Finally, the potential CCS benefit of biochar when finally disposed in the soil is compared with the reference end-of-life stage of peat substrates simply by comparing their decay behaviour over time as an open-field application.

\subsubsection{System boundary and functional unit}

The system boundary includes the collection and processing of the residues and the operation of the biochar plant. To understand the current reference system and how the Enerchar system and products are compared to the reference, a detailed explanation of the new technology is provided here.

The reference system for the energy generation is a natural gas boiler, commonly used for heat and power generation at small scales. Current practices in the use of peat in greenhouses require its replacement at every new crop seeding. Peat is one of the most frequently used substrates and covers over $90 \%$ of a substrate's volume. Biochar can replace peat on a one-to-one basis. The $\mathrm{CO}_{2}$ from flue gas can be captured and used directly in the greenhouse as a gaseous fertiliser; however, the use of $\mathrm{CO}_{2}$ as fertilizer is neglected in this study for both the reference and the Enerchar system. A change in greenhouse gas soil emissions due to possible fertiliser reductions was not considered in this stage because of a lack of data. The carbon storage in the recalcitrant part of biochar is considered to be a negative $\mathrm{CO}_{2}$ flux. The biochar is assumed to not change the soil $\mathrm{pH}$, nitrogen fertiliser inputs or the soil fertility, nor is it assumed to affect soil emissions. The same crop yields and watering needs are assumed regardless of the use of biochar. We assume biochar replaces peat based on equal functionality and equal quantity.

The reference greenhouse facility uses a natural gas boiler to cover its heat demands and uses peat in the substrates. The proposed co-production facility covers its 13 MW heat demand by a syngas boiler and uses biochar in the substrates, which corresponds to $3,000 \mathrm{~kg} \cdot \mathrm{h}-1$ biomass input and $3 \mathrm{~m}^{3} \cdot \mathrm{h}^{-1}$ of co-produced biochar. The biomass to biochar mass ratio is 0.1 (or $10 \%$ of the mass) on a dry matter basis.

Data on the electricity mix, fossil fuel origin and domestic heat production are specific to the Netherlands as far as available. Otherwise, an EU electricity mix is used.

Setting the system boundaries as such is aimed at identifying the processes and flows considered in the LCA study. Figure 2 illustrates the processes included within the system boundary. In the reference situation, a natural gas boiler provides heat for a greenhouse and peat is extracted for use in substrates. In the proposed system, the feedstock biomass is collected and transported to a gasifier, where syngas and biochar are produced at $700^{\circ} \mathrm{C}$. The biochar replaces an equal amount of white peat in horticulture substrates, and after its use in the greenhouse, it is incorporated in the soil as a soil improver, possibly by mixing it with compost to activate the biological activity and increase its nutrient loading. The processes include (a) the production of syngas and biochar, (b) the use of the syngas and biochar products vs fossil heat and peat and finally (c) the end of life (disposal) of biochar vs peat.

The use and disposal stage considers the use of syngas combustion for heat and the management of the products' disposal after the use phase. The assumption is that the spent biochar is disposed in the soil, providing carbon sequestration.

The functional unit describes the main function of a system and facilitates the quantification of the environmental performance of a product or system to compare it with alternatives and the current system. The functional unit acts as a 


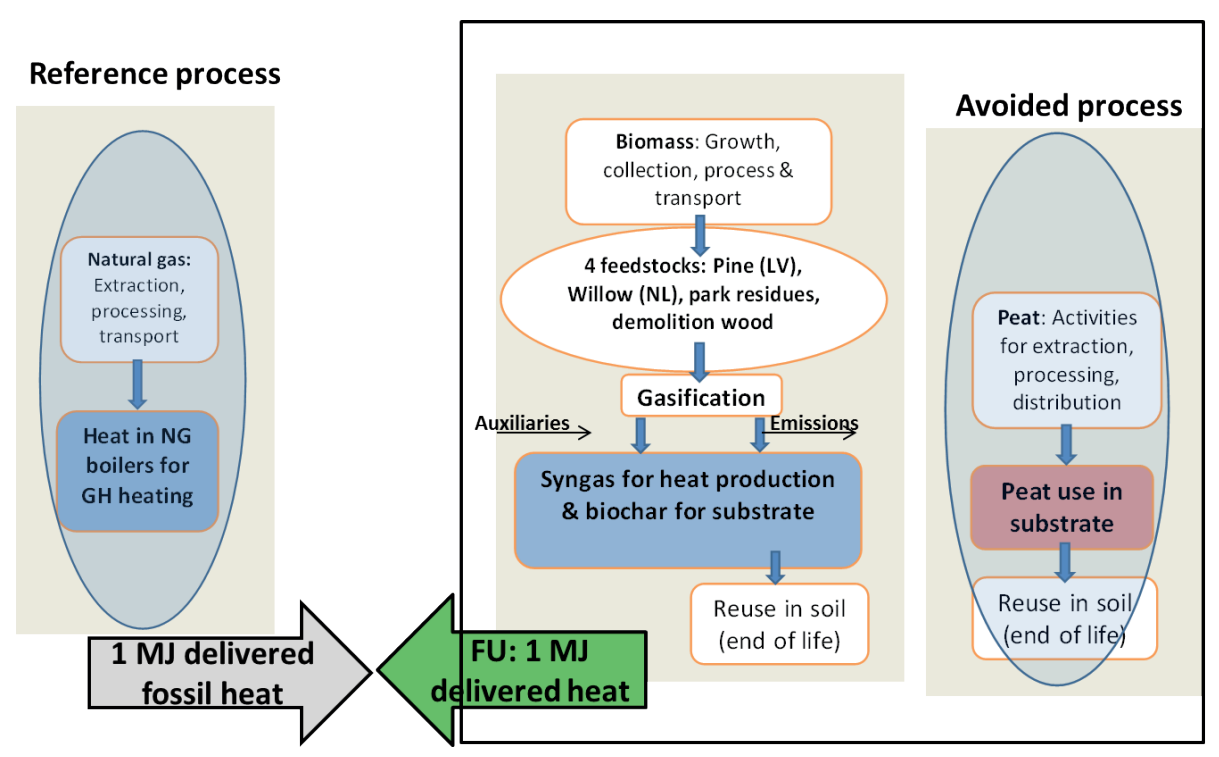

FIGURE 2: System boundaries of the syngas plus biochar system.

reference to relate inputs to outputs. In this study, the principal function of the Enerchar system is the delivery of energy; therefore, the functional unit is defined as the delivery of 1 MJ heat. The co-produced biochar is linked with this energy production and is therefore included in the functional unit.

\subsubsection{Life-cycle inventory phase}

The $\mathrm{LCl}$ includes the material and process streams in the system-namely, natural resources, auxiliary energy, chemicals, emissions to air, effluents to soil and water. At the end of this phase, the $\mathrm{LCl}$ is complete, which SimaPro converts to a table with hundreds of elementary flows. Although the inventory results provide the most detail, the interpretation of this long list of material flow needs to be done in a standardised manner regulated by the ISO standards for LCAs.

The data for the auxiliary electricity was obtained from the ecoinvent database of the Dutch electricity mix, available through SimaPro. Transport and handling data on the biomass input were obtained mainly from the ecoinvent database (ecoinvent, 2016). Conventional diesel trucks transporting willow, wood pellets and park residues within the Netherlands $(50 \mathrm{~km})$ and pine from Latvia $(700 \mathrm{~km})$ are used in the $\mathrm{LCl}$. The relevant processes for the preparation of the feedstock were considered too, such as harvesting, baling and manual or mechanical work.

The data inventory of the co-products (i.e., syngas, biochar) were obtained from lab-scale trials at ECN (Fryda \& Visser, 2015). For the end-of-life emissions to the air (i.e, combustion of syngas), data were taken from the literature and from the ecoinvent database v.3.4. The timing of $\mathrm{CO}_{2}$ emissions associated with the growth, harvest and decay of biomass, peat and biochar is addressed separately in Section "Detailed carbon balance", where the $\mathrm{CO}_{2}$ emissions calculations from the growth and decay of biomass are presented along with the emissions from feedstock collection, handling and transport.

\section{Feedstock}

Pine from Latvia and willow from the Netherlands were considered, both of which come from intensive forestry, pellets from demolition wood and residues from municipal parks in the Netherlands.

Intensive forestry wood. The Netherlands imports of wood products increased 5.3\% in 2017 (globalwood, nd). Although Sweden and Germany remain important suppliers of fuelwood and industrial roundwood to the Netherlands, the Baltic States have experienced a growth in wood pellet production in the recent years, and the imports from Latvia are on a continuous rise (IEA 2012). We assume pinewood was transported an average distance of $700 \mathrm{~km}$ from Latvia using $32,000 \mathrm{~kg}$ trucks.

Cultivated short-rotation coppice (SRC) willow. SRC willow is a second-generation bioenergy crop (like Miscanthus), which is favoured for its rapid accumulation of biomass and carbon accumulation in soil. We assume SRC willow is produced in NL and is transported a distance of $50 \mathrm{~km}$ using $32,000 \mathrm{~kg}$ trucks.

Municipal park residues. This refers to residues from activities carried out by the municipality to preserve and maintain the parks. Roundwood is used for wood products (e.g., furniture, construction), and material not applicable for use in products is converted to wood chips, which mainly supply wood boilers. The harvest of the total of these woody residues never exceeds wood growth, and sufficient residues are left in the soil during the maintenance process to secure the return of nutrients and the accumulation of soil carbon. In addition, the produced wood products and wood chips are certified by the Forest Stewardship Counsil (FSC) through the Dutch municipal forest management body Stadsbosbeheer. The FSC certification guarantees that the wood streams from national and municipal parks and forests fulfil criteria on an environmental, societal and economic level (FSC Principles and Criteria for Forest Stewardship, 2015). These criteria ensure that (1) the production of timber, non-timber products and ecosystem 
services maintains the forest's biodiversity, productivity, and ecological processes, (2) both local people and society enjoy long term benefits from the forest management and (3) forest operations are structured and managed so as to be sufficiently profitable but not at the expense of the forest resource, the ecosystem, or affected communities. In our study, we assume that only chips made from woody residues unsuitable for use in products are used for energy. This is a waste stream that needs some treatment in any case. As such, the $\mathrm{CO}_{2}$ flux from growth, decay and combustion has not been calculated.

Demolition wood (grade $A$ waste wood). This stream consists of processed residual wood that comes from wood products (e.g., construction boards, furniture) and does not contain any chemicals or contaminants. The classification follows the Dutch coding system (EURAL, Europeese Afvalstoffenslijst, in Eurowaste, n.d.). The environmental impact of this feedstock is assumed to have been allocated to the main product, and demolition wood is a waste stream that needs treatment. As in the previous stream described above, the $\mathrm{CO}_{2}$ flux from growth, decay and combustion is not relevant for this waste stream. Currently, grade A wood pellets are co-fired in coal power plants in the Netherlands. It is a constrained resource, which means that any increase in the demand for this feedstock will not lead to an increase of its production and availability, and this may create competition among users and shortages that will need to be covered by alternative sources. We considered the worstcase scenario, where a shortage in grade $A$ wood pellets in the power sector will be compensated by an increase of pine wood consumption of equal heat content (HHV in $\mathrm{MJ} / \mathrm{kg}$ ). The energy produced from a grade $A$ wood pellet is $1.65 \mathrm{kWh} / \mathrm{kg}$ wood based on its heating value of $13 \mathrm{MJ}$ - $\mathrm{kg}-1$ and assuming its electricity efficiency $35 \%$. As pine wood has a higher heating value compared with grade $A$ wood pellets, a replacement ratio of 1:0.75 is considered.

Data on the forest wood feedstock supply and properties are shown in Table 1. These data are used in the calculation of the $\mathrm{CO}_{2}$ emissions from the feedstock supply chains.

Auxiliary energy consumption. This concerns utilities

TABLE 1: Data on forest wood supply and properties, annual growth and yield data (sources given in the NOTES section).

\begin{tabular}{|c|c|c|}
\hline \multirow{2}{*}{ Description } & \multicolumn{2}{|c|}{ Wood type } \\
\hline & Pinus sylvestris & Willow \\
\hline Transport (km) & 700 & 50 \\
\hline Moisture (\%w/w) & $50^{1}$ & $10^{1}$ \\
\hline Calorific value, MJ/kg & $17^{2}$ & $17^{2}$ \\
\hline Rotation time (years) & 30 & 2 or $3^{3}$ \\
\hline $\begin{array}{l}\text { Biomass Annual Growth } \\
\left(\mathrm{m}^{3} / \mathrm{ha}^{*} \mathrm{y}\right)\end{array}$ & 8 & $29^{4}$ \\
\hline Basic Wood Density $\left(t_{d m} / m^{3}\right)$ & $0.42^{5}$ & $0.42^{5}$ \\
\hline $\begin{array}{l}\text { Carbon factor } \\
(C \text { content in wood })\left(\mathrm{tC} / \mathrm{m}^{3}\right)\end{array}$ & $0.51^{6}$ & $0.5^{5}$ \\
\hline $\begin{array}{l}\text { Ratio Below to Above ground } \\
\text { biomass (B.G./A.G.) }\end{array}$ & $0.29^{7}$ & $0.25^{8}$ \\
\hline $\begin{array}{l}\text { Biomass Conversion \& Expan- } \\
\text { sion Factor BCEFS }\left(\mathrm{t}_{\mathrm{dm}} \cdot \mathrm{m}^{-3}\right)\end{array}$ & $0.75^{9}$ & 1 \\
\hline
\end{tabular}

such as the process heating and power necessary for running the processes. The data are taken from the ecoinvent database for the European market. Wherever available, data for the Dutch context are used (IEA, 2014).

Peat extraction and use. A valuable source of data is the report ordered by EPAGMA (European Peat and Growing Media Association), carried out by Quantis, Switzerland (Peano et al., 2012), as well as our own calculated data presented in Section 2.3. According to Hagberg and Holmgren (2008), emissions and uptake of greenhouse gases from pristine bogs can differ significantly among different bog types and vary with climatic conditions, but in our study, we made some assumptions in order to simplify the calculations. The used data refer to peat extraction in Finland, decay data for peat in soil are taken from Hayes and Wilson (1997) and data for land use are taken from ecoinvent and the IPCC (2014b).

Open-cast mine infrastructure for peat is considered. Peat extraction contributes to $\mathrm{CO}_{2}$ release because these relatively young carbon stocks oxidise very quickly. The effect of infrastructure on the impact assessment results is minor and is therefore omitted. In addition, the transport of peat from Finland is considered to be $700 \mathrm{~km}$.

Natural gas. Natural gas is delivered at high pressure. The natural gas life cycle starts with its extraction and ends in the combustion facility. Beside the large-scale consumers of natural gas, such as power generators, natural gas enters local distribution systems that deliver it to residential and commercial consumers via low-pressure, small-diameter pipelines. Infrastructure was also considerednamely, an industrial natural gas furnace and a synthetic gas factory that approximates the Enerchar facility.

Tables 2-4 summarise the physical properties of bio-

TABLE 2: Properties of biochar, peat, syngas and natural gas.

\begin{tabular}{|c|c|}
\hline \multicolumn{2}{|c|}{ Physical properties } \\
\hline Dry matter content, peat & $98 \%$ \\
\hline Peat Density $\left(\mathrm{kg} \mathrm{m}^{-3}\right)$ & 110 \\
\hline Peat C content, dm \% & 50 \\
\hline Dry matter content, biochar & $98 \%$ \\
\hline Biochar Density $\left(\mathrm{kg} \mathrm{m}^{-3}\right)$ & 110 \\
\hline Biochar C content, dm \% & 80 \\
\hline Density, Ngas kg m³ & 0.717 \\
\hline Calorific value, Ngas MJ kg-1 & 46 \\
\hline Density, syngas $\mathrm{kg} \mathrm{m}^{-3}$ & 1.15 \\
\hline Calorific value, syngas $\mathrm{MJ} \mathrm{kg}^{-1}$ & 9 \\
\hline
\end{tabular}

TABLE 3: Properties of biochar and peat.

\begin{tabular}{l|cc}
\hline Property & Peat moss & Biochar (wood base) \\
\hline $\mathrm{pH}$ & $6.5(5.1-7.5)$ & $8-10$ \\
\hline Bulk density $\left(\mathrm{gcm}^{-3}\right)$ & 0.21 & $0.1-0.2$ \\
\hline $\mathrm{CEC}\left(\mathrm{cmol} \mathrm{kg}^{-1}\right)$ & 93.8 & $\mathrm{n} . \mathrm{m}$ \\
\hline $\mathrm{EC}\left(\mathrm{dSm}^{-1}\right)$ & 0.365 & $0.5-0.8$ \\
\hline $\mathrm{CaCO}_{3}$ & $<1.0 \%$ & n.m \\
\hline
\end{tabular}


TABLE 4: Emissions per fuel (natural gas, syngas) in a boiler (UNFCC, n.d.)

\begin{tabular}{|c|c|c|}
\hline \multicolumn{3}{|c|}{ Emission factors (kg/GJ) } \\
\hline & Syngas & Natural gas \\
\hline Carbon dioxide & & 57 \\
\hline Carbon monoxide & 0.036 & 0.02 \\
\hline Nitrogen oxides & 0.028 & 0.030 \\
\hline \multicolumn{3}{|l|}{ Dinitrogen monoxide } \\
\hline Methane, biogenic & 0.0001 & 0.0001 \\
\hline Sulfur dioxide & 0.005 & 0.005 \\
\hline $\begin{array}{l}\text { NMVOC, non-methane VOC, unspe- } \\
\text { cified origin }\end{array}$ & 0.0003 & 0.0003 \\
\hline
\end{tabular}

char and peat and the emissions per GJ of fuel combustion, introduced in the SimaPro input/output sheet. The density and caloric value of the syngas produced in the biomass gasifier is calculated based on its main gas components.

\section{Detailed carbon balance}

The 100-year global warming potential (GWP100), as set by the IPCC 2013, is used in all cases. Generally, no distinction is made between fossil and biogenic carbon. The timing of emissions is accounted for by applying the Bern carbon cycle model for various emission times over a 0-100 year timescale and the IPCC GWP values. This is further described in Sections $a$ and $b$.

a. Monitoring of biomass carbon flux as biomass growth, harvest and use and decay of residues

To calculate the carbon source and sink relations between the soil and the atmosphere, it is necessary to gain data on the carbon dynamics of the feedstock in the soil (i.e., growth, decay) and further interpret them into $\mathrm{CO}_{2}$ emissions. Figure 3 shows the global carbon flows in the atmosphere.

In our study, we consider carbon as participating in the following processes or pools, as shown in Figure 3, ignoring the ocean carbon pool:

- The growth of biomass through photosynthesis, which is linked with $\mathrm{CO}_{2}$ uptake over a certain period;

- Harvesting biomass (e.g., thinning, pulpwood, harvested energy plantations and agricultural production); although biomass will grow again, harvesting will result in instantaneous $\mathrm{CO}_{2}$ release and initially reduced carbon absorption;

- Leaving residues to decay above and below ground. This is organic matter left in a field or plantation after harvesting; for example, straw or forest residues, sawmill and wood manufacturing residues and residues from agriculture crops. These materials will decay if they are not valorised;

- Biochar and peat incubated in the soil.

The effect of biomass is relevant for climate-impact calculations when converted to energy and carbon products because of variable decay rates and atmospheric carbon uptake during growth. When using woody biomass from trees with long rotation times, carbon uptake from the regrowth of new plants will take place over a period of several years, while its combustion creates instantaneous $\mathrm{CO}_{2}$ emissions. In contrast, when using biomass from fast-rotating resources, the instantaneously released $\mathrm{CO}_{2}$ will remain in the atmosphere for a much shorter time due to the accelerated growth and carbon-uptake rate of those plants. Fast-decaying biomass residues emit GHG if not

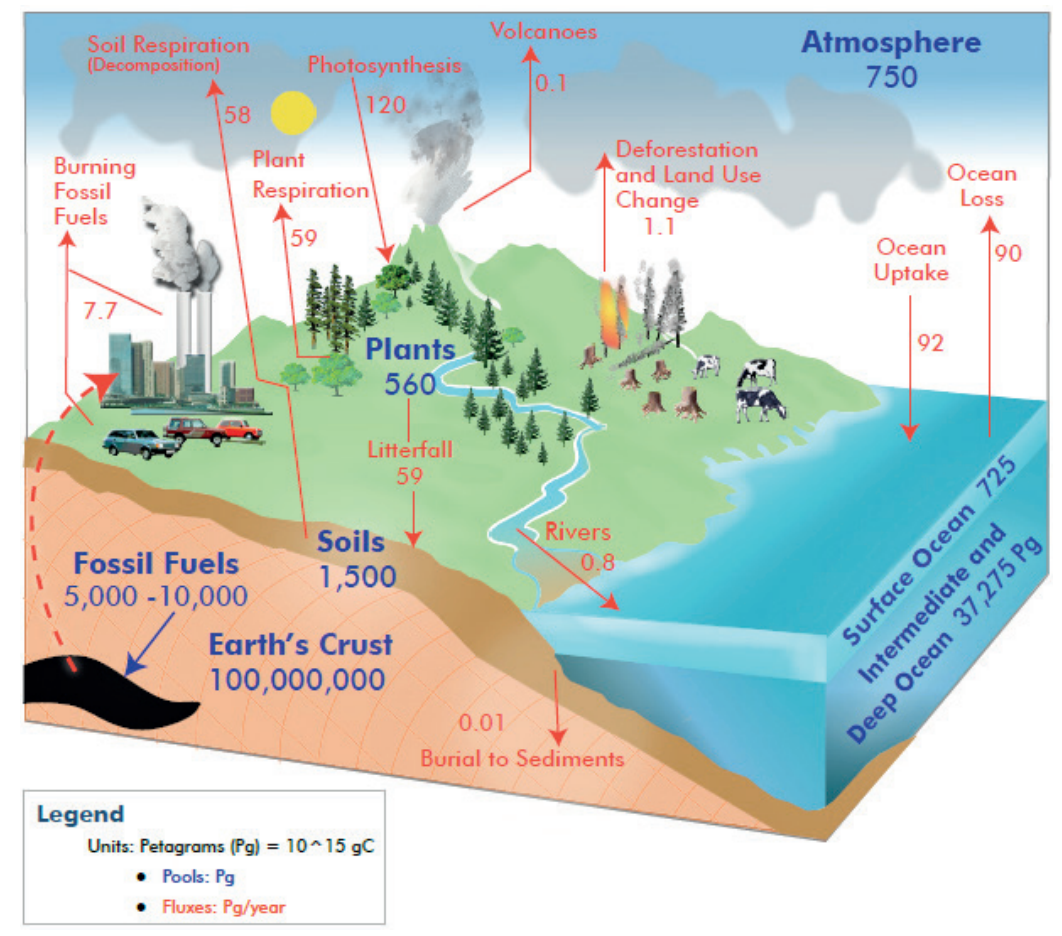

FIGURE 3: The global carbon cycle, carbon pools and carbon fluxes (The Carbon Cycle Project, 2010). 
handled, which needs to be accounted for, especially if $\mathrm{CH}_{4}$ is released during decay.

The methodology applied in the study follows the work by Schmidt and Brandao (2013), which is briefly presented in this section. We assume that the harvest takes place in year $\mathrm{t}=0$ and that $\mathrm{CO}_{2}$ is immediately release from the combustion of biomass. After the harvest, the plant starts growing and stores carbon. The rate of biomass growth of forestry crops is based on the following general logistic (S-shaped or sigmoid) equation:

$$
N P P(t)=\frac{N P P_{T}}{1+100^{\frac{T / 2-t}{T / 2}}}
$$

where $\mathrm{NPP}(\mathrm{t})$ is the yield (net primary production) in a specific year $\mathrm{t}(\mathrm{kg}$ carbon or $\mathrm{kg}$ biomass), NPP(t) is the total yield over the whole rotation ( $\mathrm{kg}$ carbon or $\mathrm{kg}$ biomass), $\mathrm{t}$ is the time (years) variable and $\mathrm{T}$ is the rotation length in years.

During the same period, the residues that have not been harvested start decaying, emitting $\mathrm{CO}_{2}$ as well. The decay of wood residues follows a negative exponential model as proposed by Freschet et al. (2012). The ROTHC-26.3 model by Coleman and Jenkinson (2008) was applied. The theory and the methodology of its application are given by Schmidt and Brandao (2013).

The carbon balance over a 100-year period considers the emissions from instantaneous bioenergy conversion, the emissions of residues left to decay, the carbon stored during the growth phase (i.e., avoided emissions) and the emissions from the use of biochar or peat. Following this, the annual carbon flux due to the harvest and use biomass, growth and decay and its contribution to global warming is calculated using the modified $\mathrm{GWPCO}_{2}, \Delta \mathrm{t}$ factor. This factor is the ratio of the $\mathrm{CO}_{2}$ emitted at time $\Delta \mathrm{t}$ (time delay) to the $\mathrm{CO}_{2}$ emitted at time 0 . The $\mathrm{CO}_{2}$ emitted at time $\Delta \mathrm{t}$ and 0 are the integrals of the Bern carbon cycle equation, which describe the fraction of $\mathrm{CO}_{2}$ that remains in the atmosphere after a period of time. While biomass combustion emits $\mathrm{CO}_{2}$ following a pulse response function (meaning $\mathrm{CO}_{2}$ is instantaneously emitted), $\mathrm{CO}_{2}$ uptake during growth and decay happens gradually, and its effects are subject to a delay. Integrating the modified $\mathrm{CO}_{2}$ flux over the years of the rotation time gives the final $\mathrm{CO}_{2}$ emission value for the bioenergy system. The same approach is followed for peat and biochar use, considering only its gradual decay in the soil.

\section{b. Estimation of the biochar carbon sequestration potential}

Biochar from herbaceous and woody feedstock sources have a carbon content of $60 \%-70 \%$ and $75 \%-90 \%$, respectively, of which a certain part can be considered stable over centuries depending on their production conditions. The storage of stable biochar carbon in the soil means the long-term removal of carbon. Biochar from woody feedstocks produced at the Enerchar gasifier at ECN has a carbon content value as high as $85 \%$ on a dry weight basis. Data on biochar's stability and half-life is based on proxy test data (specifically, tests that compared the oxidation degree of biochar to graphite) as well as on modelling (Hammond et al., 2011; Cross \& Sohi, 2013). Based on a moderate assumption that $70 \%$ of the biochar carbon is recalcitrant in the long term, for every $\mathrm{kg}$ of biochar carbon applied in the soil, $\sim 0.7 \mathrm{~kg}$ of carbon can be sequestered (Myers, 2011), which is equivalent to $\sim 2.56 \mathrm{CO}_{2}$ eq per $\mathrm{kg}$ biochar carbon.

To calculate the decay of peat and biochar at any time $t$, we applied the exponential decay function of carbon in soil proposed by Hammond et al. (2011) and Field et al. (2013), from which we can calculate the sequestration potential of biochar as the remaining fraction of the undecayed carbon. The direct carbon sequestration value of biochar can be estimated in $\mathrm{CO}_{2}$-equivalent terms according to the following equation:

$\mathrm{CO}_{2, \text { sequestration }}(t)=3.66 \cdot \mathrm{No}\left(1-e^{\frac{-t \ln (2)}{t 1 / 2}}\right)$

where 3.66 is the ratio of the molecular weight of $\mathrm{CO}_{2}$ to that of carbon, No is the initial carbon quantity and $t_{1 / 2}$ is the half-life of biochar in soil. The sequestration value of the char varies from 0 to $3.66 \mathrm{~kg} \mathrm{CO}_{2}$ eq per $\mathrm{kg} \mathrm{bi}$ ochar carbon as recalcitrance increases. In the case of peat, the proposed half-life is 16 years, an average value proposed by Hayes et al. (1997), and the half-life of biochar is assumed to be 200 years, a value in line with the data presented in Cross and Sohi (2013), Hammond et al. (2011), Field et al. (2013) and Myers (2011). The $\mathrm{CO}_{2}$ sequestration value is $2.98 \mathrm{~kg} \mathrm{CO}_{2 \text { eq }}$ per kg biochar carbon according to the above equation with a time horizon of 100 years. The delay of $\mathrm{CO}_{2}$ emissions has also been considered in line with the $\mathrm{CO}_{2}$ emissions balance for the biomass feedstocks supply chain. Peat will have totally decayed in a 100 years' time frame, as its half-life is 16 years.

\section{Direct and indirect land use changes}

In the case where the biomass to be valorised in a bioenergy project is grown on uncultivated land, this will cause a direct land-use change (dLUC). If biomass grown on existing arable land is used for bioenergy instead of food, this will likely cause indirect land-use changes (iLUC) because the food production will be pushed to another location where it may replace another current land use. Due to changes in the carbon stock of the soil and the biomass, iLUC has consequences in the greenhouse gas balance of the bioenergy project. Around $11 \%$ of global GHG emissions originate from land use changes.

A comprehensive definition of iLUC, according to Schmidt et al. (2015), includes the upstream consequences of the use of a plot of land, i.e., changes that are transmitted across global markets linked by commodity substitutability and competition for land. Because iLUC effects cannot be measured directly, they must be determined by modelling the effect of each land-occupying activity on global land use.

The model applied to calculate the iLUC was developed by 2.-0 LCA (iLUC model, 2013) and is applicable to all regions in the world and to all types of land use. The standard reference flow of the use of land, 'land tenure', is the land's production capacity measured in $\mathrm{kg}$. This is converted to land usage measured in hectares per year (ha yr-1).

Table 5 shows the GWP100 as $\mathrm{CO}_{2}$ eq emissions from 
the carbon-balance calculations, considering growth and decay functions according to the presented theory and the references and includes iLUC-related GHG emissions using the model described in the previous paragraph. These GWP100 values are then introduced in the SimaPro input sheet in the emissions section as fossil $\mathrm{CO}_{2}$ emissions.

\subsubsection{Impact assessment}

Following the $\mathrm{LCl}$, the impact of the proposed process on the environment can be assessed. This phase is the LCIA, which aims to explain and evaluate the magnitude and significance of the potential impacts of a product system on the environment. This stage is further sub-divided into classification, characterisation and weighting.

During classification, the inventoried emissions are assigned to impact categories according to the substances' ability to contribute to different environmental issues. Various methods are used to relate the collected input/output data with midpoint impact category indicators (Humbert et al., 2005; Acero et al., 2015). For our inventory, we chose the IMPACT 2002+ method, which includes the most critical emissions included in our processes; for example, emissions from the combustion of gaseous fuels. During characterisation, the emissions are multiplied with a characterisation factor (CF) that reflects their relative environmental impact, allowing a direct comparison and grouping; for example, methane and $\mathrm{CO}_{2}$ both contribute to global warming but with different effects per kg substance. The final steps are normalisation and weighting (normalisation is not used in the current study). Weighting was used in our study to assess the relative importance of different impact categories (e.g., global warming versus respiratory effects). The impact assessment results are discussed in the following chapter.

\section{RESULTS AND DISCUSSION}

\subsection{Biochar stability tests}

The biochar samples are summarised in Table 6. The table includes materials providing extreme reference points with respect to carbon stability, which were also tested, such as commercially produced graphite, active carbon and fresh biomass. Considering the mass reduction, knowing the initial and final carbon mass percentage, ash and moisture in the sample, biochar's carbon stability can be

TABLE 5: Calculated GWP100 for feedstock and soil substrates (biochar and peat), excluding transport and handling.

\begin{tabular}{l:l}
\multicolumn{2}{c}{ Feedstock chain GWP100 emissions } \\
\hline Pinewood (LV) & $0.060069 \mathrm{~kg}$ per kgwood \\
\hdashline Willow (NL) & $-0.091115 \mathrm{~kg}$ per kgwood \\
\hline Park residues (NL) & - \\
\hline Grade A wood (NL) & - \\
\hline Biochar (peat subst.) & $-238 \mathrm{~kg} \mathrm{~m}^{-3}$ biochar \\
\hline Peat use & $147 \mathrm{~kg} \mathrm{~m}^{-3}{ }_{\text {peat }}$ \\
\hline Peat extraction & $0.113 \mathrm{~kg} \mathrm{~m}_{\text {peat }}^{-3}$ \\
\hline
\end{tabular}

expressed as the proportion of initial carbon remaining after treatment.

$C \%=\frac{B_{a} \cdot C_{b a}}{B_{i} \cdot C_{b i}}$

$B_{a}$ is the residual biochar after oxidation, $C_{b a}$ is its carbon content on a dry basis, $B_{i}$ is the initial mass of biochar prior to treatment and $\mathrm{C}_{\mathrm{bi}}$ is the initial carbon content of the biochar. The results are shown in Table 6.

The test results confirm the high carbon stability of graphite and active carbon and the low stability of fresh biomass. Even though this method is not standard, it gives a good estimation of carbon stability by comparing different materials with the reference materials, graphite and fresh biomass. Our assumption in this work on biochar's carbon stability is therefore valid.

\subsection{Environmental impact assessment results}

\subsubsection{Environmental impact of the feedstock supply chains}

This section discusses the environmental impact of the feedstock supply chains (i.e., the four biomass feedstocks) per one kg feedstock as an initial step before the main environmental impact assessment results, which refer to the functional unit of the Enerchar system (1 MJ heat production) shown in the next paragraph. This initial step provides a good impression of the effect feedstock choice can have on the overall environmental impact of any bioenergy project. The characterised results of the environmental impact of the four feedstock supply chains per one kg produced is shown in Table 7. Latvian pine imported to the Netherlands demonstrates the largest impact mainly due to the elevated $\mathrm{CO}_{2}$ associated with its long rotation times and long-distance transport. The fact that pine trees grow over a period of at least 30 years render it very likely that the $\mathrm{CO}_{2}$ released from the use of the wood for energy at the end of this period will remain long enough in the atmosphere to contribute to the global warming potential, as explained in Section 2 of the paper. The claim that biomass is carbon neutral is not valid in this case.

Figure 4a shows the relative impact of the four supply chains per kg feedstock. To reduce the large number of impact categories, weighting was performed. An alternative weighting calculation developed by Weidema (2009) and Weidema et al. (2008), which is included in the Step-

TABLE 6: Stability of biochar expressed as carbon that remained after the oxidation tests.

\begin{tabular}{l|c}
\hline Biochars \& control & $\begin{array}{c}\text { \% Carbon in } \\
\text { oxidized biochar }\end{array}$ \\
\hline Wood (park residue) biochar, gasification $670^{\circ} \mathrm{C}$ & 90.0 \\
\hline Beech wood / pine wood, gasification $670^{\circ} \mathrm{C}$ & 97.5 \\
\hline Commercial biochar * & 98.0 \\
\hline Pine wood biochar, gasification $670^{\circ} \mathrm{C}$ & 89.5 \\
\hline Cocoa biochar, pyrolysis at $630^{\circ} \mathrm{C}$, steam activated & 98.1 \\
\hline Graphite * & 99.0 \\
\hline Active Carbon ${ }^{*}$ & 99.0 \\
\hline Active Carbon 2 * & 99.0 \\
\hline Fresh cocoa shell & 25.3 \\
\hline
\end{tabular}


TABLE 7: Characterized results for the four feedstock considered. The results refer to $1 \mathrm{~kg}$ feedstock.

\begin{tabular}{|c|c|c|c|c|c|}
\hline Impact category & Unit & Pine & Park residues & Willow & Grade A pellets \\
\hline Global warming & $\mathrm{kg} \mathrm{CO}_{2}^{\text {eq }}$ & 0.486 & 0.0283 & 0.129 & 0.515 \\
\hline Respiratory inorganics & $\mathrm{kg} \mathrm{PM} 2.5$ eq & 0.000169 & $3.16 \mathrm{E}-05$ & $9.991 \mathrm{E}-05$ & 0.0002 \\
\hline Non-renewable energy & MJ primary & 1.320 & 0.437 & 0.972 & 1.758 \\
\hline Carcinogens & $\mathrm{kg} \mathrm{C}_{2} \mathrm{H}_{3} \mathrm{Cl}$ eq & 0.000621 & 0.0002 & 0.0005 & 0.0008 \\
\hline Non-carcinogens & $\mathrm{kg} \mathrm{C}_{2} \mathrm{H}_{3} \mathrm{Cl}$ eq & 0.000708 & 0.000385 & 0.000642 & 0.00109 \\
\hline Ionizing radiation & $\mathrm{Bq} \mathrm{C}-14$ eq & 0.423 & 0.127 & 0.279 & 0.551 \\
\hline Ozone layer depletion & $\mathrm{kg} \mathrm{CFC}-11^{\text {eq }}$ & $1.45 \mathrm{E}-08$ & 4.89E-09 & $1.11 \mathrm{E}-08$ & $1.94 \mathrm{E}-08$ \\
\hline Respiratory organics & $\mathrm{kg} \mathrm{C}_{2} \mathrm{H}_{4}$ eq & $5.112 \mathrm{E}-05$ & $1.31 \mathrm{E}-05$ & $3.49 \mathrm{E}-05$ & $6.51 \mathrm{E}-05$ \\
\hline Aquatic ecotoxicity & $\mathrm{kg}$ TEG water & 5.074 & 2.202 & 4.152 & 7.276 \\
\hline Terrestrial ecotoxicity & kg TEG soil & 1.784 & 1.184 & 1.935 & 2.969 \\
\hline Terrestrial acid/nutri & $\mathrm{kg} \mathrm{SO}_{2}^{\text {eq }}$ & 0.00381 & 0.000519 & 0.00190 & 0.00432 \\
\hline Land occupation & $\mathrm{m}^{2}$ org.arable & 0.00331 & 0.00102 & 0.00191 & 0.00433 \\
\hline Aquatic acidification & $\mathrm{kg} \mathrm{SO}_{2}$ eq & 0.000614 & 0.000105 & 0.000328 & 0.000719 \\
\hline Aquatic eutrophication & kg PO4 P-lim & $1.39 \mathrm{E}-05$ & 4.91E-06 & $9.98 \mathrm{E}-06$ & $1.88 \mathrm{E}-05$ \\
\hline Mineral extraction & MJ surplus & 0.00215 & 0.000991 & 0.0015 & 0.00314 \\
\hline
\end{tabular}

wise2006 method and available to download from 2.-0 LCA, was applied to check if the same impact categories were identified as being equally important as in the IMPACT 2002+ weighting phase. This validation step is presented in the LCA report by The Eco Ferry Consortium (2013). The weighted results are shown in Figures $4 \mathrm{~b}$ and $4 \mathrm{c}$ and confirm that, indeed, the most significant impact categories are respiratory inorganics (particle emissions) and global warming (GHG emissions), while non-renewable energy consumption (auxiliary energy and materials) was identified as important by the IMPACT 2002+ weighting phase but not by Stepwise2006. Based on this check, we will assume that the results have a satisfactory degree of credibility concerning these two specific impact categories. Although this check, the weighing of the characterised results using a second method as a validation step, was repeated throughout the study, we chose to not show this procedure again. The validation was carried out, and, in all cases, the most significant impact categories were indeed respiratory inorganics (particle emissions), global warming (GHG emissions) and non-renewable energy consumption (auxiliary energy and materials).

The results among the feedstock chains show a large variation, which is due to several reasons explained in this section. Pine and willow trees have different agronomic properties, especially concerning growth times, carbon uptake and root storage characteristics. Willow appears to be a promising candidate in bioenergy and biofuels production due to its short rotation. Transitions from arable to SRC (poplar or willow) or perennial grasses (Miscanthus or switchgrass) can result in increased carbon accumulation in soil (Harris et al., 2015). The park residues form a waste stream; as such, they do not participate in the growth and decay carbon cycle. In addition, park residues are currently abundant in the Netherlands, and therefore, no competing end uses have yet been recorded. In contrast, grade
A pellets from clean demolition wood, although classified as a waste stream, are a restricted resource with competing alternative end uses in the power sector; therefore, the creation of a shortage will lead to an increase of alternative fuel consumption, which we assume is pine wood (the worst-case scenario). Of course, willow could also replace the currently used pellets in power plants, reducing the final impact results. However, we do not consider park residues as a candidate fuel in the power sector in this stage because they are a blend of various trees and plants with fluctuating properties over the year, often containing salts in the ash that cannot be handled easily in a power plant's high-temperature furnace. Grade A pellets have a certified and standard average composition, which is necessary to safeguard the continuous operation of a large power plant.

\subsubsection{Environmental impact of $1 \mathrm{MJ}$ process heat delivery}

Based on the results shown section 3.2.1, willow wood was chosen as the feedstock for the impact assessment of the Enerchar system because of its satisfactory environmental performance compared to pine. Park residues show an even better environmental performance; however, willow wood is a promising, high-quality, fast-growing wood and a realistic candidate for large-scale bioenergy projects because of its good and standardised quality, as opposed to the fluctuating physical properties of park residues. The environmental impact of the main processes contributing to the production of $1 \mathrm{MJ}$ of bioenergy from willow, including biochar production, is presented in Table 8 (characterised results), and their relative contribution is shown in Figures 5a and b applying the IMPACT 2002+ method. Each column in the figures represents the environmental impact of the sub-processes per category. The results are presented per MJ heat delivered, which is the functional unit, and include the impact avoided by replacing peat with biochar as well as the CCS potential of bio- 
(a)
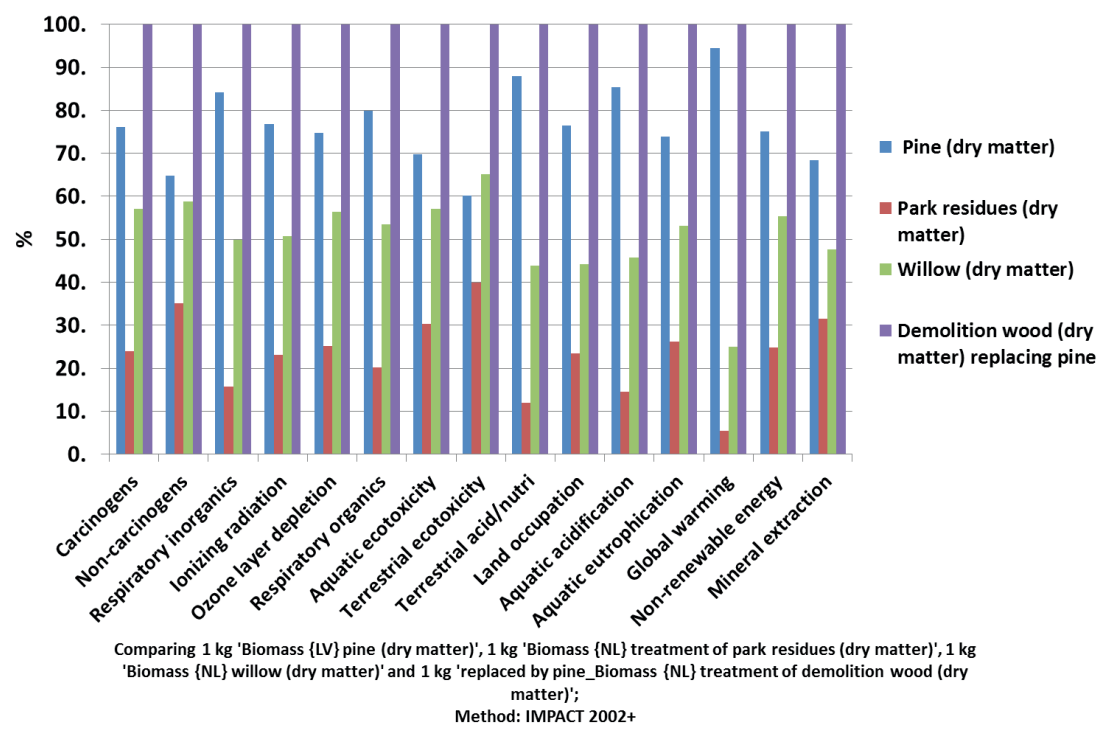

(b)

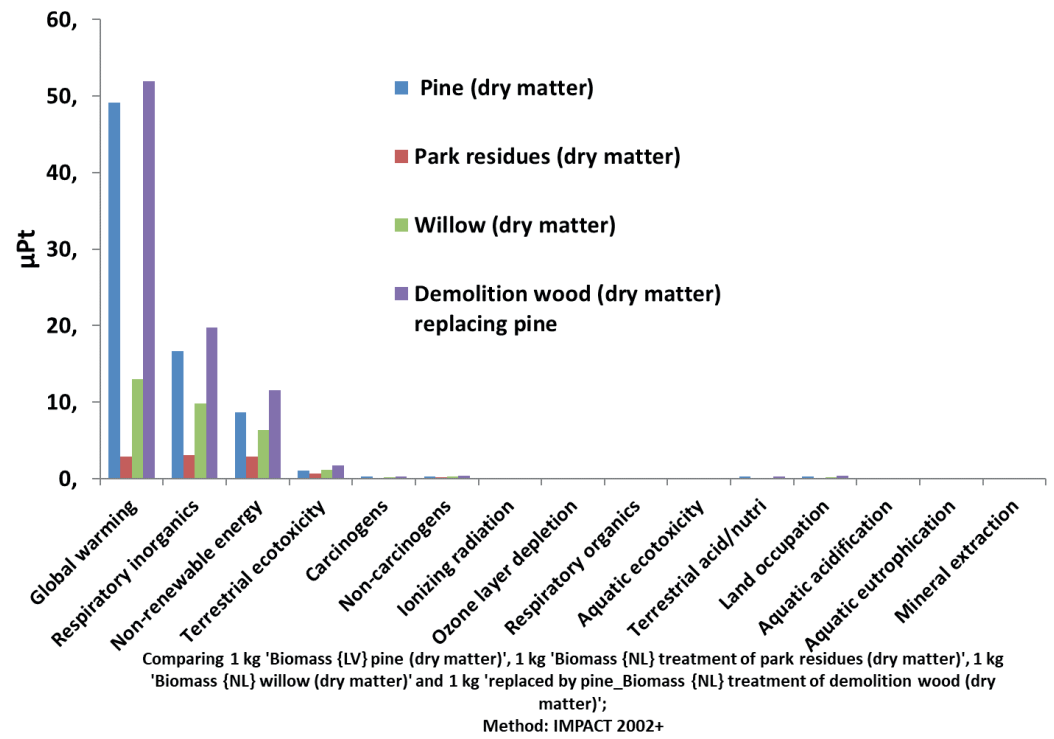

(c)

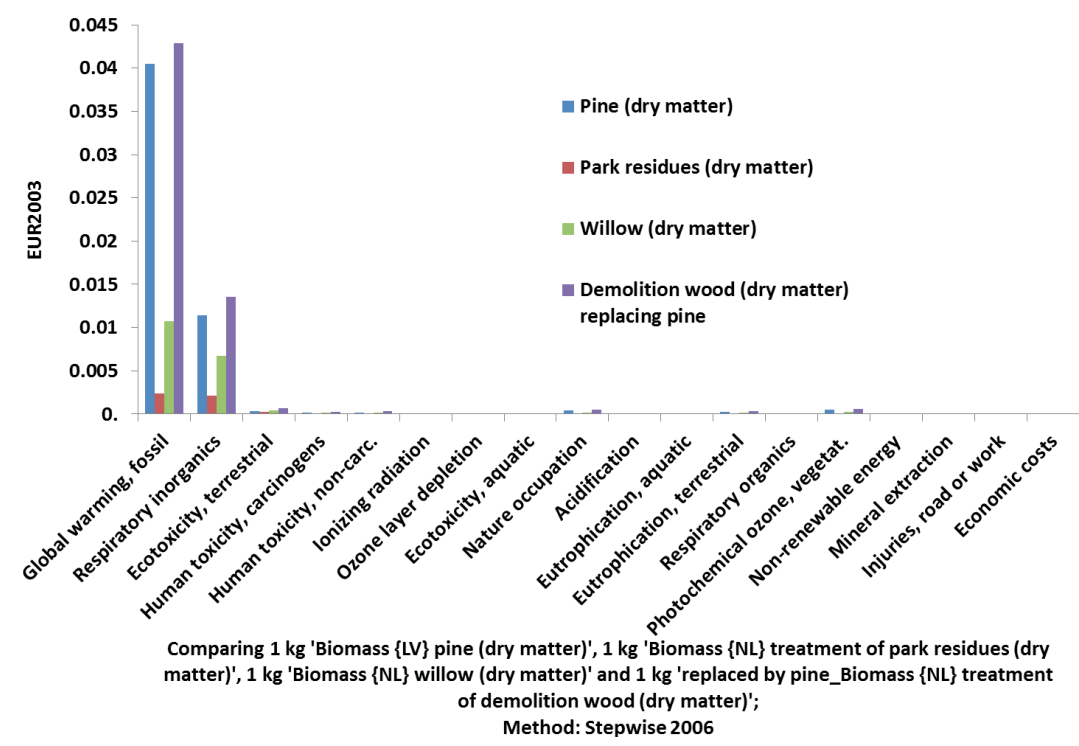

FIGURE 4: Comparison of the four selected feedstocks supply chains from growth to harvest per kg feedstock: (a) characterised results, (b) results after weighting with IMPACT 2002+ and (c) results after weighting with Stepwise2006. 
TABLE 8: Characterised impact results for 1 MJ heat (including the use of biochar) based on willow wood.

\begin{tabular}{|c|c|c|c|c|c|}
\hline Impact category & Unit & Total & $\begin{array}{l}\text { Emissions from } \\
\text { syngas boiler }\end{array}$ & $\begin{array}{l}\text { Gasification } \\
\text { process }\end{array}$ & $\begin{array}{c}\text { Gas boiler } \\
\text { infrastructure }\end{array}$ \\
\hline Global warming & $\mathrm{kg} \mathrm{CO}_{2}$ eq & -0.0113 & $9.64 \mathrm{E}-05$ & -0.0119 & 0.000459 \\
\hline Respiratory inorganics & kg PM2.5 eq & $1.12 \mathrm{E}-05$ & $3.62 \mathrm{E}-06$ & $6.44 \mathrm{E}-06$ & $1.15 \mathrm{E}-06$ \\
\hline Non-renewable energy & MJ primary & 0.113 & 0 & 0.108 & 0.00475 \\
\hline Carcinogens & $\mathrm{kg} \mathrm{C}_{2} \mathrm{H}_{3} \mathrm{Cl}$ eq & $9.421 \mathrm{E}-05$ & 0 & 7.4E-05 & $2.03 E-05$ \\
\hline Non-carcinogens & $\mathrm{kg} \mathrm{C}_{2} \mathrm{H}_{3} \mathrm{Cl}$ eq & 0.000125 & 0 & $8.62 \mathrm{E}-05$ & $3.9 \mathrm{E}-05$ \\
\hline Ionizing radiation & $\mathrm{Bq} \mathrm{C}-14$ eq & 0.0529 & 0 & 0.0543 & -0.00146 \\
\hline Ozone layer depletion & kg CFC-11 eq & $8.31 \mathrm{E}-10$ & 0 & $8.01 \mathrm{E}-10$ & $2.97 \mathrm{E}-11$ \\
\hline Respiratory organics & $\mathrm{kg} \mathrm{C}_{2} \mathrm{H}_{4}{ }^{\text {eq }}$ & $4.072 \mathrm{E}-06$ & $1.2 \mathrm{E}-06$ & $2.58 \mathrm{E}-06$ & $2.83 \mathrm{E}-07$ \\
\hline Aquatic ecotoxicity & $\mathrm{kg}$ TEG water & 0.382 & 0 & 0.277 & 0.104 \\
\hline Terrestrial ecotoxicity & $\mathrm{kg}$ TEG soil & 0.153 & 0 & 0.112 & 0.041 \\
\hline Terrestrial acid/nutri & $\mathrm{kg} \mathrm{SO}_{2}$ eq & 0.000301 & 0.000154 & 0.000141 & $6.47 \mathrm{E}-06$ \\
\hline Land occupation & $\mathrm{m}^{2}$ org.arable & 0.000108 & 0 & $9.161 \mathrm{E}-05$ & $1.68 \mathrm{E}-05$ \\
\hline Aquatic acidification & $\mathrm{kg} \mathrm{SO}_{2}$ eq & 4.67E-05 & $1.99 \mathrm{E}-05$ & $2.442 \mathrm{E}-05$ & $2.41 \mathrm{E}-06$ \\
\hline Aquatic eutrophication & kg P04 P-lim & $1.6 \mathrm{E}-06$ & 0 & $8.86 \mathrm{E}-07$ & 7.11E-07 \\
\hline Mineral extraction & MJ surplus & 0.000557 & 0 & 0.000144 & 0.000413 \\
\hline
\end{tabular}

(a)

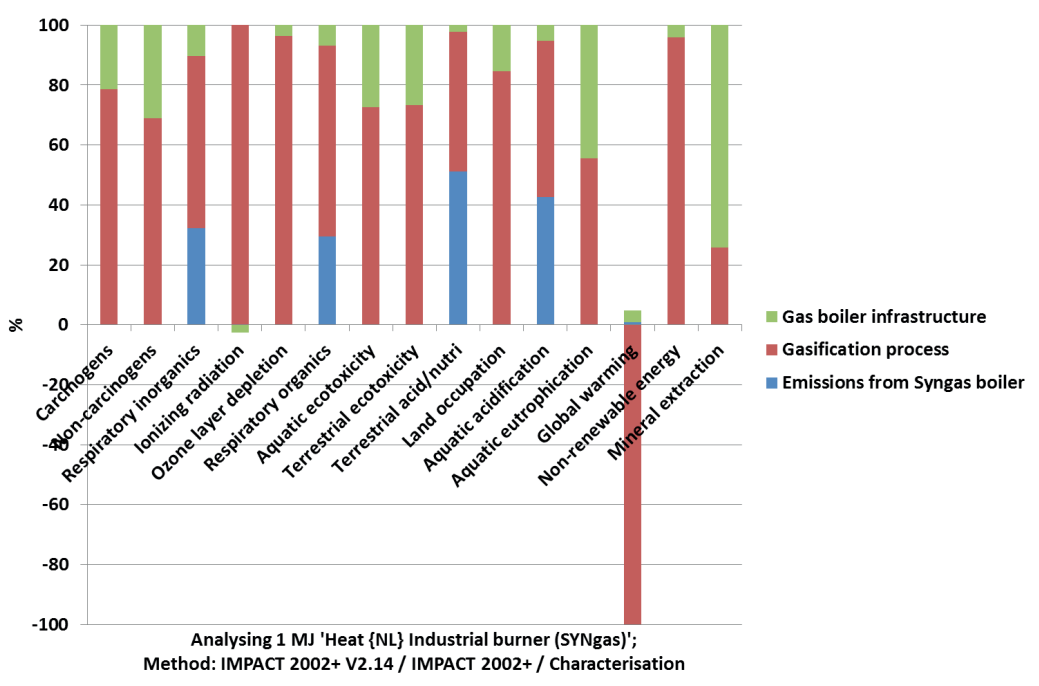

(b)

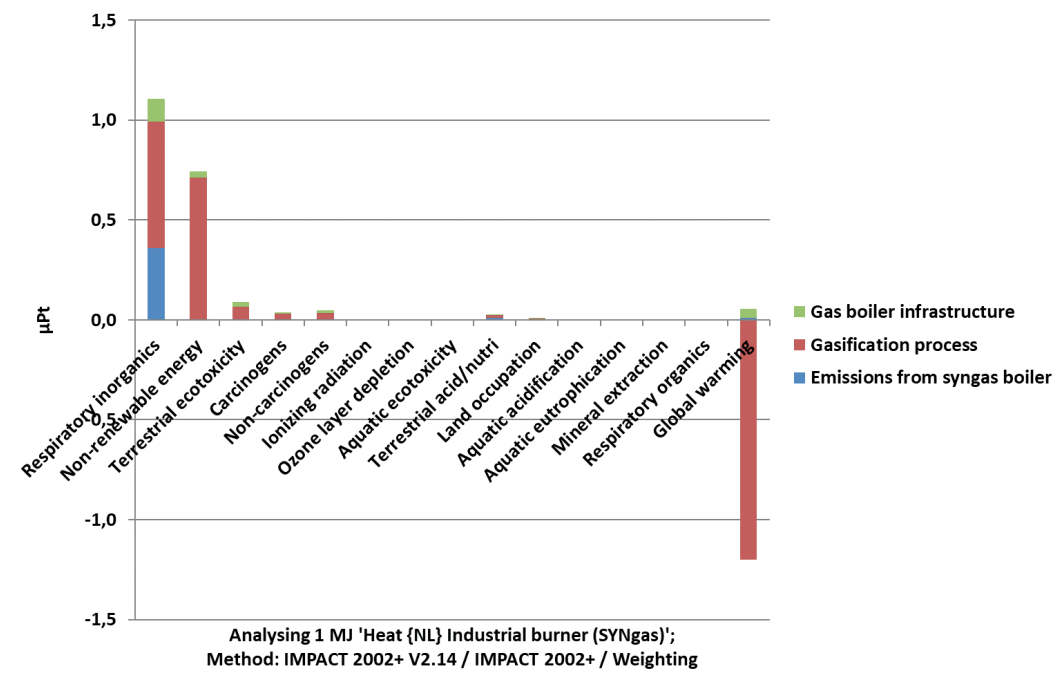

FIGURE 5: Breakdown of the final impact (IMPACT 2002+ method) of 1 MJ heat (including biochar) based on willow: (a) characterised results and (b) weighted results. 
char as a disposal option, thereby avoiding the disposal of peat.

The combustion of syngas contributes to the total impact because of NOx and particulate emissions of respiratory inorganics that affect health (i.e., process emissions from industrial burners). From Figure 5, which shows the relative contribution of the sub-processes to the total impact of gasification, it can be concluded that the gasification process is a large contributor to the total impact; therefore, a detailed analysis of the syngas production impact is shown in Figure 6. The characterised results of the environmental impact of the syngas production only are shown in Table 9.

The feedstock supply chain (in the case shown here for willow) is an important environmental impact contributor, as confirmed in Section 3.2.1. A smaller impact is due to the use of grid electricity for auxiliaries in the plant (electricity, medium voltage). Transport does not contribute to the overall results and is not shown at all. The use of stable biochar carbon instead of peat shows climate change mitigation and CCS potential, as the negative value in the 'Cli- mate Change' bar shows (biochar, utilisation of biochar as peat substitute). This value includes avoiding the use and disposal of peat in addition to using biochar and storing it in the soil after use.

\subsubsection{Comparison of the Enerchar system with natural gas heating}

Figures 7a and $b$ show the environmental impact of replacing $1 \mathrm{MJ}$ of fossil heat (natural gas) with syngas-based heat, considering all four feedstocks. The characterised results are shown in Table 10. We assume that natural gas is supplied by the Dutch natural gas grid and heating is provided by industrial natural gas burners. As with all previous results, the avoided impact of peat uses and its end-of-life uses as well as the CCS potential of biochar in soil after its use have been taken into account in the functional unit, which is the $1 \mathrm{MJ}$ of delivered heat. In addition, the negative values in the Climate Change bar represent $\mathrm{CO}_{2}$ storage because of the biochar carbon stored in the soil after its use as a peat replacement.

The use of willow and park residues result in overall

(a)

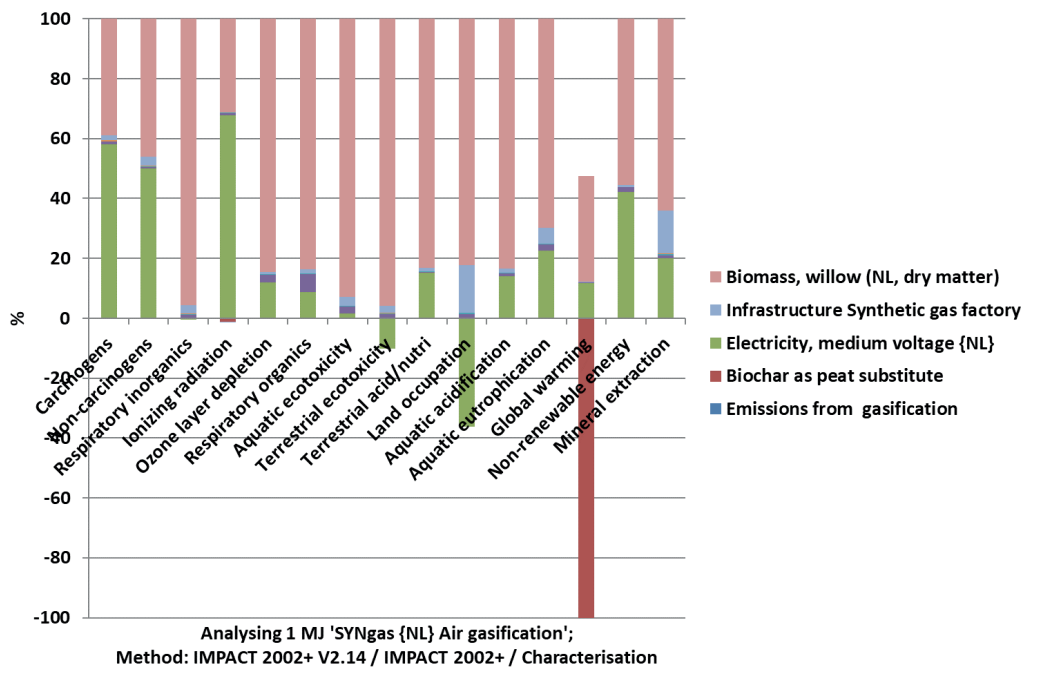

(b)

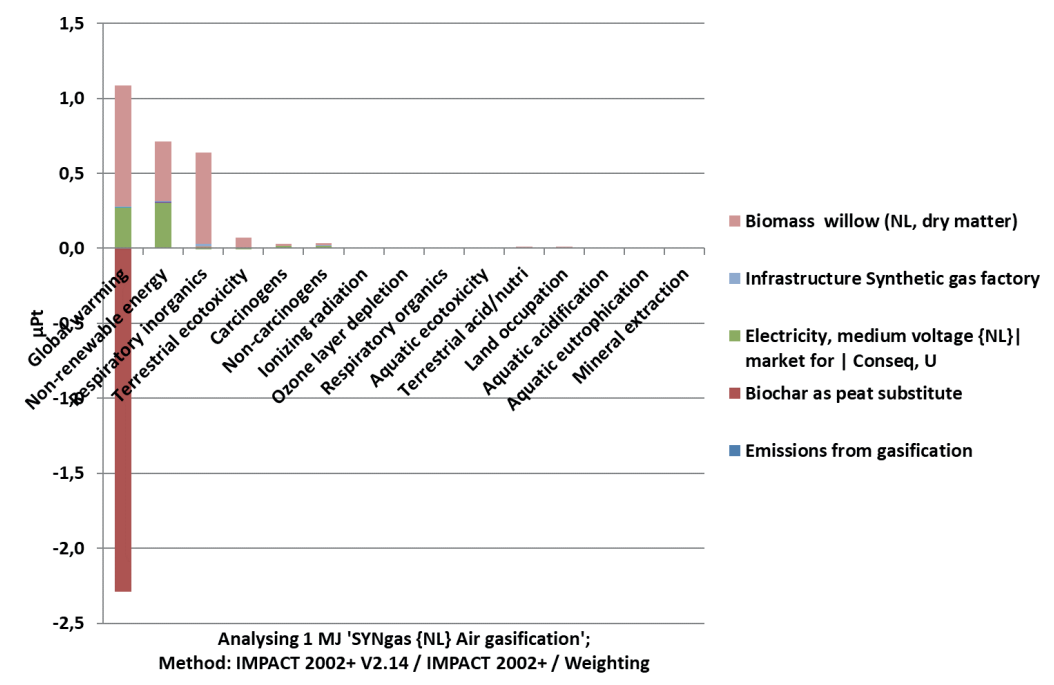

FIGURE 6: Breakdown of the environmental impact (IMPACT 2002+ method) of $1 \mathrm{MJ}$ of produced gas (including biochar) based on willow: (a) characterised results and (b) weighted results. 
TABLE 9: Characterised impact results for $1 \mathrm{MJ}$ of produced gas based on willow wood.

\begin{tabular}{|c|c|c|c|c|c|c|}
\hline Impact category & Unit & Total & $\begin{array}{l}\text { Biochar as peat } \\
\text { substitute }\end{array}$ & $\begin{array}{c}\text { Electricity, } \\
\text { medium voltage }\end{array}$ & $\begin{array}{l}\text { Syngas factory } \\
\text { Infrastructure }\end{array}$ & Biomass, willow \\
\hline Global warming & $\mathrm{kg} \mathrm{CO}_{2}$ eq & -0.0119 & -0.0227 & 0.00266 & $6.26 \mathrm{E}-05$ & 0.0079 \\
\hline Respiratory inorganics & kg PM2.5 eq & $6.44 \mathrm{E}-06$ & $-4.5 \mathrm{E}-09$ & $-2.7 \mathrm{E}-08$ & $1.87 \mathrm{E}-07$ & $6.19 \mathrm{E}-06$ \\
\hline Non-ren.energy & MJ primary & 0.108 & -0.00011 & 0.0456 & 0.000654 & 0.0602 \\
\hline Carcinogens & $\mathrm{kg} \mathrm{C}_{2} \mathrm{H}_{3} \mathrm{Cl}$ eq & 7.4E-05 & $-3.1 E-08$ & 4.3E-05 & $1.12 \mathrm{E}-06$ & $2.88 \mathrm{E}-05$ \\
\hline Non-carcinogens & $\mathrm{kg} \mathrm{C}_{2} \mathrm{H}^{\text {eq }}$ & $8.62 \mathrm{E}-05$ & $-6.6 \mathrm{E}-08$ & 4.31E-05 & $2.51 \mathrm{E}-06$ & $3.98 \mathrm{E}-05$ \\
\hline Ionizing radiation & $\mathrm{Bq} \mathrm{C}-14$ eq & 0.0543 & -0.00064 & 0.0374 & -0.00015 & 0.0173 \\
\hline Ozone layer depletion & kgCFC-11 eq & $8.01 \mathrm{E}-10$ & $-8.6 \mathrm{E}-13$ & $9.64 \mathrm{E}-11$ & $4.92 \mathrm{E}-12$ & $6.79 \mathrm{E}-10$ \\
\hline Respiratory organics & $\mathrm{kgC}_{2} \mathrm{H}_{4}{ }^{\mathrm{eq}}$ & $2.58 \mathrm{E}-06$ & $-1.4 \mathrm{E}-09$ & $2.27 \mathrm{E}-07$ & $3.83 \mathrm{E}-08$ & $2.16 \mathrm{E}-06$ \\
\hline Aquatic ecotoxicity & kgTEG water & 0.277 & -0.00032 & 0.00464 & 0.00819 & 0.257 \\
\hline Terrestrial ecotoxicity & kg TEG soil & 0.112 & $-6.8 \mathrm{E}-05$ & -0.0126 & 0.00307 & 0.12 \\
\hline Terrestrial acid/nutri & $\mathrm{kg} \mathrm{SO}_{2}$ eq & 0.000141 & $-7.3 \mathrm{E}-08$ & 2.13E-05 & $1.46 \mathrm{E}-06$ & 0.000118 \\
\hline Land occupation & $\mathrm{m}_{2}$ org.arable & $9.16 \mathrm{E}-05$ & $-4 \mathrm{E}-08$ & $-5.2 \mathrm{E}-05$ & $2.28 \mathrm{E}-05$ & 0.000118 \\
\hline Aquatic acidification & $\mathrm{kg} \mathrm{SO}_{2} \mathrm{eq}$ & 2.44E-05 & $-1.3 \mathrm{E}-08$ & $3.4 \mathrm{E}-06$ & $3.43 \mathrm{E}-07$ & $2.04 \mathrm{E}-05$ \\
\hline Aquatic eutrophication & kg P04 P-lim & $8.86 \mathrm{E}-07$ & $-1.1 \mathrm{E}-09$ & $2 \mathrm{E}-07$ & 4.83E-08 & $6.19 \mathrm{E}-07$ \\
\hline Mineral ext. & MJ surplus & 0.000144 & $-4.4 \mathrm{E}-07$ & $2.9 \mathrm{E}-05$ & $2.05 \mathrm{E}-05$ & $9.27 \mathrm{E}-05$ \\
\hline
\end{tabular}

TABLE 10: Comparison of the characterized impact results between natural gas and syngas based heat (Functional Unit $=1$ MJ heat produced).

\begin{tabular}{|c|c|c|c|c|c|c|}
\hline Impact category & Unit & $\begin{array}{l}\text { Heat Household } \\
\text { burner (Natural } \\
\text { gas) }\end{array}$ & $\begin{array}{c}\text { Heat in syngas } \\
\text { boiler (pine) }\end{array}$ & $\begin{array}{l}\text { Heat in syngas } \\
\text { boiler (willow) }\end{array}$ & $\begin{array}{c}\text { Heat in syngas } \\
\text { boiler (park) }\end{array}$ & $\begin{array}{c}\text { Heat in syngas } \\
\text { boiler } \\
\text { (Grade A pellet) }\end{array}$ \\
\hline Global warming & $\mathrm{kg} \mathrm{CO}_{2}$ eq & 0.0608 & 0.0108 & 0.0113 & 0.0176 & 0.0125 \\
\hline Respiratory inorganics & kg PM2.5 eq & $8.361 \mathrm{E}-06$ & $1.552 \mathrm{E}-05$ & $1.122 \mathrm{E}-05$ & $6.981 \mathrm{E}-06$ & $1.742 \mathrm{E}-05$ \\
\hline Non-ren. energy & MJ primary & 1.369 & 0.135 & 0.113 & 0.0799 & 0.162 \\
\hline Carcinogens & $\mathrm{kg} \mathrm{C}_{2} \mathrm{H}_{3} \mathrm{Cl}$ eq & 0.00236 & 0.000104 & $9.42 \mathrm{E}-05$ & $7.75 \mathrm{E}-05$ & 0.000116 \\
\hline Non-carcinogens & $\mathrm{kg} \mathrm{C}_{2} \mathrm{H}_{3} \mathrm{Cl}$ eq & 7.19E-05 & 0.000129 & 0.000125 & 0.000109 & 0.000153 \\
\hline Ionizing radiation & $\mathrm{Bq} \mathrm{C}-14$ eq & 0.0151 & 0.0618 & 0.0529 & 0.0435 & 0.0697 \\
\hline Ozone layer depletion & kg CFC-11 eq & 4.71E-09 & $1.05 \mathrm{E}-09$ & $8.31 \mathrm{E}-10$ & $4.55 \mathrm{E}-10$ & $1.35 \mathrm{E}-09$ \\
\hline Respiratory organics & $\mathrm{kg} \mathrm{C}_{2} \mathrm{H} 4$ eq & $5.20 \mathrm{E}-06$ & $5.13 \mathrm{E}-06$ & 4.071E-06 & $2.72 \mathrm{E}-06$ & $5.951 \mathrm{E}-06$ \\
\hline Aquatic ecotoxicity & $\mathrm{kg}$ TEG water & 0.418 & 0.438 & 0.381 & 0.261 & 0.575 \\
\hline Terrestrial ecotoxicity & kg TEG soil & 0.117 & 0.144 & 0.153 & 0.107 & 0.217 \\
\hline Terrestrial acid/nutri & $\mathrm{kg} \mathrm{SO}_{2}$ eq & 0.000217 & 0.000421 & 0.000301 & 0.000216 & 0.000452 \\
\hline Land occupation & $\mathrm{m}^{2}$ org.arable & 3.61E-05 & 0.000195 & 0.000108 & 5.3E-05 & 0.000258 \\
\hline Aquatic acidification & $\mathrm{kg} \mathrm{SO}_{2}^{\text {eq }}$ & 3.19E-05 & $6.43 \mathrm{E}-05$ & 4.672E-05 & 3.283E-05 & $7.081 \mathrm{E}-05$ \\
\hline Aquatic eutrophication & kg PO4 P-lim & $1.003 \mathrm{E}-06$ & $1.84 \mathrm{E}-06$ & $1.60 \mathrm{E}-06$ & $1.28 \mathrm{E}-06$ & $2.14 \mathrm{E}-06$ \\
\hline Mineral extraction & MJ surplus & 0.00051 & 0.000597 & 0.000557 & 0.000526 & 0.000659 \\
\hline
\end{tabular}

carbon storage, as reflected by the negative values of the Climate Change indicator, which translates into favourable environmental behaviour (negative $\mathrm{CO}_{2}$ flux). Willow is a fast-growing tree with a high annual yield that requires minimal fertilisation, and its root system can store carbon during its growth. Municipal park residues are a waste that does not burden the carbon cycle and seems to be a promising feedstock for low-temperature conversion routes, as in the proposed Enerchar technology. The extensive use of grade A wood is expected to create a shortage of this feedstock, which will finally push the use of alternative woody feedstocks of the same quality; the worst case of importing pine wood was chosen and is shown in the results.

These results highlight the importance of the chosen biomass resource given its influence on the timing of $\mathrm{CO}_{2}$ release vs storage and the importance of biochar's carbon stability in soil, which transforms the disposal of a spent substrate into a CCS tool. In addition, any competing or alternative use of the feedstock in the case of a constrained feedstock, such as grade A wood pellets from demolition wood, can influence the results strongly. The degree of handling and transport play a less important role. 
(a)

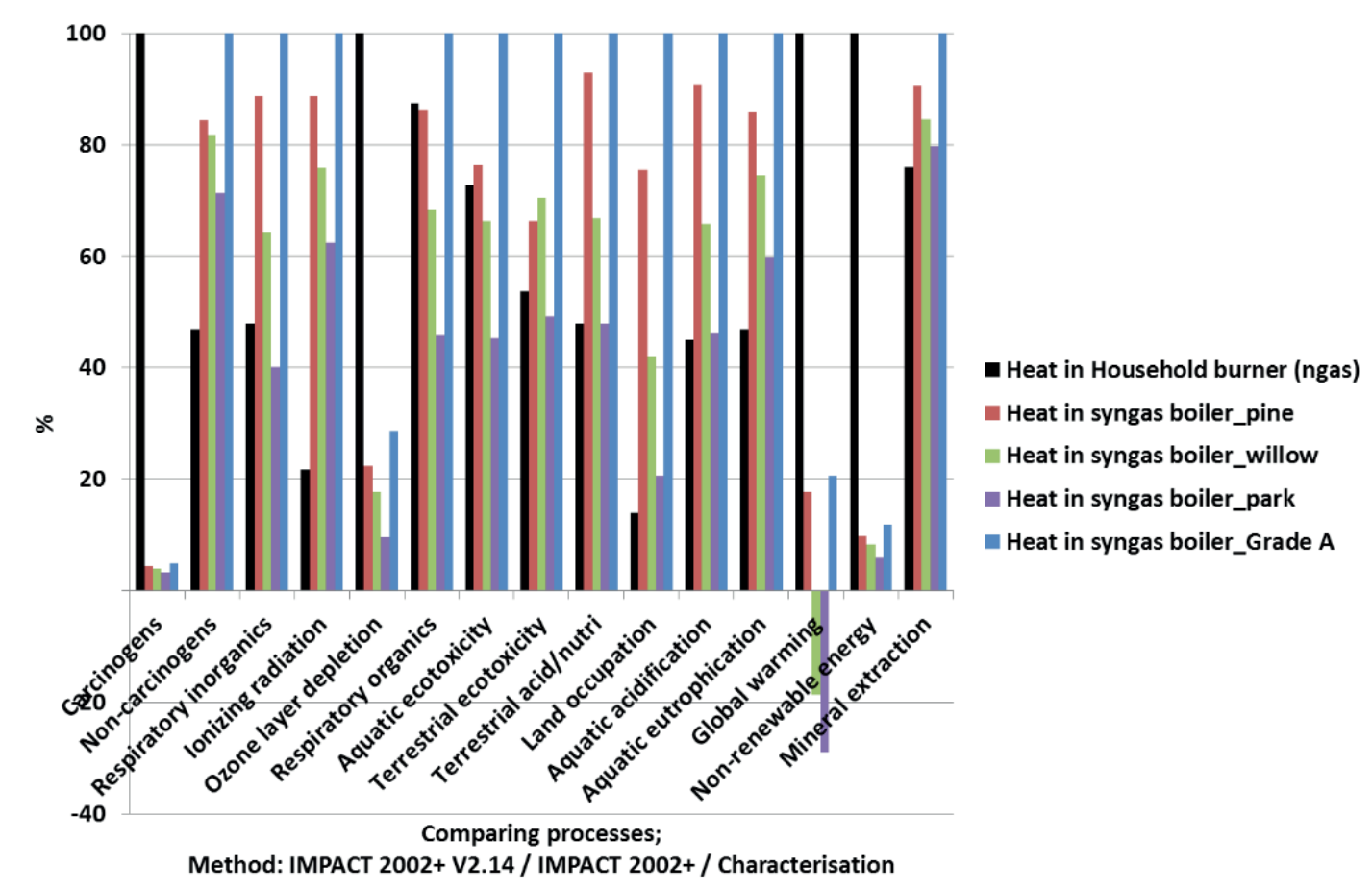

(b)

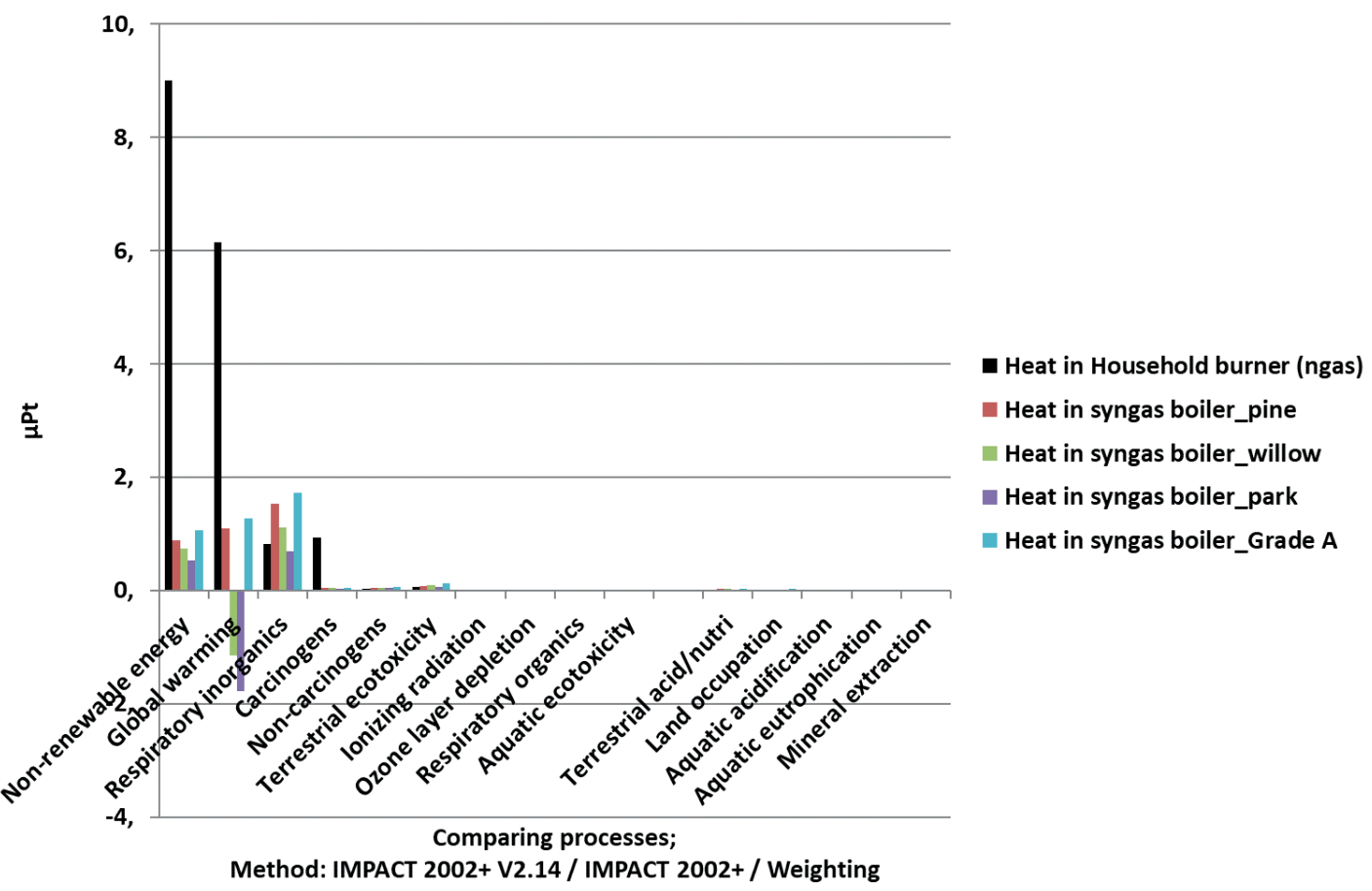

FIGURE 7: Comparison of $1 \mathrm{MJ}$ of heat delivered using the four feedstock types with the reference natural gas heating: (a) characterised results and (b) weighted results.

\subsection{Comments on the choice of the method (IM- PACT 2002+)}

Among the methods used to categorise the large list of inventoried emissions into specific impact categories in an LCA, none considers the total amount of compounds and material streams of the inventory. It is a matter of choice and of weighting the positive vs negative aspects of each method that guides the choice of the method used for char- acterising and normalising the results. We chose the IMPACT 2002+ method because it includes a larger number of compounds from the inventory phase in the classification and normalisation steps compared to other methods. There is no objectively right or wrong choice, though, and other arguments for another method may stand strong as well.

Finally, more important than the choice of the method is the consistency of the choices throughout the study and the clarity of the results presentation. The study aims 
to compare cases to a reference as well as to each other case in a qualitative manner rather than an absolute manner. Therefore, we believe that the choice of this particular method in combination with the validation of the results through the comparison with the weighting results from an alternative method (i.e., Stepwise 2006) provides sufficient confidence in the information presented to draw conclusions on the extent of the comparative environmental impact of the studied processes.

\section{IMPLICATIONS AND FUTURE WORK}

In this study, the environmental impact of co-producing syngas and biochar to replace natural gas and peat in horticulture has been evaluated in an attempt to identify best practices and improvement options. This study demonstrated that biochar from wood originating from tree nurseries, which was pine wood in the studied case, may not be the most sustainable option concerning its environmental impact and, specifically, its carbon footprint, although its quality would allow its direct application as a peat substrate replacement. A good, or at least acceptable, compromise is the use of fast-growing energy crops, such as SRC willow, which has much shorter rotation times, thereby reducing the net global warming effect of the released $\mathrm{CO}_{2}$. A case-by-case study is necessary when the feedstock supply chain changes.

This study reveals the importance of considering the agronomic properties of feedstocks in a detailed carbon balance, such as above- and below-ground biomass (and thus, accumulated carbon), the decay rates of biomass that remains above or below ground and the best practices for harvesting biomass in view of this information. Elaborative studies that include the carbon footprint of novel feedstocks need to be published to enable correct decisions based on a feedstock's origin.

Considerable research efforts are needed to establish standards or protocols for the long-term stability of carbon in biochar in order to include the disposal of biochar in the soil as a carbon-capture mechanism. A suggestion is the establishment of coordinated actions, including round-robin testing of the proposed carbon stability tests-mainly lab-scale chemical oxidation protocols; followed by advanced characterisation techniques, such as surface area FTIR, BET surface area and NMR; and crosschecking with proper reference char samples, for example, those originating from forest fires. The relevant literature is extensive (e.g., Spokas et al., 2010; Schmidt et al., 2018; Leng et al., 2019), and it is not within the scope of this paper to elaborate further on this matter.

Part of the life cycle of $\mathrm{CO}_{2}$ emissions are due to direct and indirect land-use changes that need to be included when biomass supply chains other than residues and waste are involved. In this study, the iLUCs due to the use of pine and willow wood were included, showing, however, a fairly insignificant contribution to the $\mathrm{CO}_{2}$ footprint of the feedstock. Even though there are several approaches proposed in the literature (e.g., Schmidt et al., 2013, 2015; Saez de Bikuña, 2017), there is no consensus on which model to use among the research community, and it is not mandatory to include iLUC analyses in studies on biofuels' carbon footprint.

Another challenging aspect is the development of a gasification system to valorise variable-quality biomass residues (e.g., straw, agro-residues, demolition wood). There is a large body of literature that considers the use of agro-residues or agro-waste and demonstrates a very broad range of biochar properties that depend on the feedstock origin and the processing conditions. A compromise can be made by blending various biomass feedstocks that have a varying impact on the final product quality (syngas and biochar) using current pyrolysis or gasification technology. A further option is to upgrade low-quality residues with fluctuating properties, such as various seasonal agro-residues, straw and roadside grass, of which the mineral concentrations are too high to match the strict requirements in horticulture. The upgrading step may include washing (leaching) minerals.

Finally, the lack of a standardised, or at least a commonly accepted, method to evaluate the environmental impact of bioenergy and biochar systems remains an obstacle towards the credible evaluation of bio-based systems. A comprehensive $\mathrm{CO}_{2}$ balance is necessary in any bio-based conversion system, including the timing of GHG emissions during growth, harvest and decay. The neutrality of biomass feedstock should not be taken for granted, but rather, a case-by-case (per feedstock) approach must be adopted.

\section{CONCLUSIONS}

Waste (residual) biomass streams, which are assumed to be $\mathrm{CO}_{2}$-neutral, will require pretreatment in conventional bioenergy conversion systems due to their high salt content. The novel low-temperature biomass gasifier Enerchar processes a variety of biomass feedstocks into syngas and biochar. The study presents the environmental impact results of the syngas and biochar production in the Enerchar gasifier, which replace natural gas with syngas for delivering process heat and replace peat with biochar in in modern greenhouses. The spent biochar substrates are disposed in the soil, where they remain for an indefinite period.

The first observation concerns the physical and agronomic properties and the growth and decay characteristics of the feedstock, which have a large contribution to the overall environmental impact of a bioenergy project. Slow-growing biomass (pine wood) shows a net $\mathrm{CO}_{2}$ release and a net global-warming potential over a 100-year time horizon for the Enerchar system. Fast-growing biomass, such as willow, shows favourable carbon-storage potential via $\mathrm{CO}_{2}$ fixation during growth. Park residues not suitable for wood products show a great potential for syngas and biochar production in low-temperature conversion installations where the fluctuating ash and salt concentrations are not as critical as in conventional higher-temperature power plant furnaces. As a conclusion, the preferred feedstock choice would be (a) residual biomass streams not applicable for any non-energy use and not competing with alternative uses, (b) a fast-growing biomass (e.g., willow) and (c) certified sustainable forest biomass.

The carbon-storage potential of biochar at the end-of- 
life phase is reflected by its carbon stability, which is a crucial parameter in this study because it directly affects the global-warming potential of the system. The high carbon stability of biochar, as verified by experiments, gives confidence in the conclusion of this study that spent biochar substrates can be disposed in the soil and can store carbon for a very long period, contributing to a net-negative carbon flux. At the same time, peat replaced by biochar also avoids the impacts related to peat extraction and use, which currently place great pressure on the environment by altering natural land areas and reducing the soil carbon sink. The combination of the carbon-storage $\left(\mathrm{CO}_{2}\right.$ offset) capacity of biochar by avoiding and replacing peat and the replacement of fossil heat by product gas heating can substantially reduce the current environmental impact of modern greenhouses.

\section{ACKNOWLEDGEMENTS}

The financial contributions of the Dutch national project TKI Enerchar and the Dutch Ministry of Economic affairs are acknowledged.

\section{NOTES}

1. Prapaspongsa et al., 2011, Appendix 3

2. https://www.ecn.nl/phyllis2

3. p.3: http://www.probos.nl/biomassa-upstream/pdf/followupFLEVOPotentialcontributionReport.pdf

4. p 25: http://www.probos.nl/biomassa-upstream/

5. IPCC $(2006$, table $4.13 \& 4.14)$

6. IPCC (2006, table 4.3)

7. IPCC (2006, table 4.4), conifers above-ground biomass 50-150 tons. ha-1

8. Fig. 4 in https://www.sciencedirect.com/science/article/pii/S096195341500149X

9. Biomass Conversion \& Expansion Factor: merchantable growing stock volume to above-ground biomass) IPCC (2006, table 4.5): Temperate pine, growing stock $41-100 \mathrm{~m}^{3}$

\section{REFERENCES}

Acero, A. P., Rodríguez, C. and Ciroth, A. (2015, March 16). LCIA methods. Impact assessment methods in Life Cycle Assessment and their impact categories. Retrieved from https://www.openlca.org/ wp-content/uploads/2015/11/LCIA-METHODS-v.1.5.4.pdf.

Blok, C., van der Salm, C., Hofland-Zijlstra, J., Streminska, M., Eveleens, B., Regelink, I., ... Visser, R. (2017). Biochar for horticultural rooting media improvement: Evaluation of biochar from gasification and slow pyrolysis. Agronomy, 7(1), 6. doi:10.3390/agronomy7010006

Chalker-Scott, L. (September 2014). Biochar: A home gardener's primer. Accessed 08/31/2018. Retrieved from http://cru.cahe.wsu. edu/CEPublications/FS147E/FS147E.pdf

Cherubini, F., Bird, N. D., Cowie, A., Jungmeier, G., Schlamadinger, B., \& Woess-Gallasch, S. (2009). Energy- and greenhouse gas-based LCA of biofuel and bioenergy systems: Key issues, ranges and recommendations. Resources, Conservation and Recycling, 53(8), 434-447

Cherubini, F., \& Strømman, A. H. (2011). Life cycle assessment of bioenergy systems: State of the art and future challenges. Bioresource Technology, 102(2), 437-451.

Consequential LCA. (n.d.). Retrieved from https://consequential-lca. org/clca/

Coleman, K., \& Jenkinson, D. S. (2008). RothC - A model for the turnover of carbon in soil. Accessed 06/26/2018. Retrieved from https:// www.rothamsted.ac.uk/sites/default/files/RothC_guide_WIN.pdf
Cross, A., \& Sohi, S. P. (2013). A method for screening the relative longterm stability of biochar. GCB Bioenergy, 5(2), 215-220.

Dispenza, V., de Pasquale, C., Fascella, G., Mammano, M. M., \& Alonzo, G. (2016). Use of biochar as peat substitute for growing substrates of Euphorbia $\times$ lomi potted plants. Spanish Journal of Agricultural Research, 14(4), e0908. http://dx.doi.org/10.5424/sjar/2016144-9082. ecoinvent (2016). https://www.ecoinvent.org/home.html

EURAL, http://www.euralcode.nl/

Eurowaste. (n.d.) Retrieved from http://www.eurowaste.be/pdf/eural-codes.pdf

Fascella. (2015). Growing substrates alternative to peat for ornamental plants. In Soilless culture. Use of substrates for the production of quality horticultural crops: InTech.

Fertiplus. (n.d.). Reducing mineral fertilizers and agro-chemicals by recycling treated organic waste as compost and bio-char. Retrieved from http://www.fertiplus.eu/Fertiplus/index.xhtml

Field, J. L., Keske, C. M., Birch, G. L., DeFoort, M. W., \& Cotrufo, M. F. (2013). Distributed biochar and bioenergy coproduction: a regionally specific case study of environmental benefits and economic impacts. GCB Bioenergy, 5(2), 177-191.

Fryda, L., \& Visser, R. (2015). Biochar for soil improvement: Evaluation of biochar from gasification and slow pyrolysis. Agriculture, 5(4), 1076-1115. doi:10.3390/agriculture5041076

Freschet, G. T., Weedon, J. T., Aerts, R., van Hal, J. R., \& Cornelissen, J. H. (2012). Interspecific differences in wood decay rates: insights from a new short-term method to study long-term wood decomposition. Journal of Ecology, 100(1), 161-170.

FSC: Principles and Criteria for Forest Stewardship Council, Document reference code: FSC-STD-01-001 V5-2 EN, Approval: 22 July 2015

Globalwood, retrieved 12/2/2018 from http://www.globalwood.org/ market/timber_prices_2018/aaw20180602e.htm

Government of the Netherlands. (n.d.) Agriculture and horticulture. Retrieved from https://www.government.nl/topics/agriculture/agriculture-and-horticulture

Hagberg, L., \& Holmgren, K. (2008). The climate impact of future energy peat production. Retrieved from https://www.ivl.se/download/18.343dc99d14e8bb0f58b7550/1445517377701/B1796.pdf

Harris, Z. M., Spake, R., \& Taylor, G. (2015). Land use change to bioenergy: A meta-analysis of soil carbon and GHG emissions. Biomass \& Bioenergery 82, 27-39. https://doi.org/10.1016/j.biombioe.2015.05.008

Hammond, J., Shackley, S., Sohi, S., \& Brownsort, P. (2011). Prospective life cycle carbon abatement for pyrolysis biochar systems in the UK. Energy Policy, 39(5), 2646-2655.

Hayes, M. H., \& Wilson, W. S. (Eds.). (1997). Humic Substances, Peats and Sludges: Health and Environmental Aspects. Elsevier.

HortiBlue-C. (n.d.). Sustainable up-cycling of agro-, agrofood and fisheries residues in horticulture and agriculture as bioenergy, biochar and chitin-rich product. Retrieved from https://www.interreg2seas. eu/en/Horti-blueC

Humbert, S., Margni, M., \& Jolliet, O. (2005). IMPACT 2002+: User guide. Draft for version 2. Retrieved from http://citeseerx.ist.psu.edu/ viewdoc/download?doi=10.1.1.454.741\&rep=rep1\&type=pdf

IEA 2012. Wood pellet production in Baltic States Task 40 Sustainable International bioenergy trade. Coordinated by Cocci. M. Retrieved 12/01/2018 from http://task40.ieabioenergy.com/wp-content/uploads/2013/09/IEA-Wood-Pellet-Study_final-july-2017.pdf

Indirect Land Use Change Model, 2013 available in https://lca-net. com/projects/show/indirect-land-use-change-model-iluc/

International Biochar Initiative. (n.d.). Biochar is a valuable soil amendment. Retrieved from http://www.biochar-international.org/biochar

Kubecek, V and Tonolo, G., (2014). Electricity Information 2014 (with data from 2013).) Retrieved from the International Energy Agency (IEA), Paris Cedex, FR IEA. ISBN 978-92-64-21692-1.

IPCC. (2013). Climate change 2013: The physical science basis. contribution of working group I to the fifth assessment report of the Intergovernmental Panel on Climate Change. IPCC: Stocker, T.F., Qin, D., Plattner, G.-K., Tignor, M., Allen, S. K., Boschung, J., . . Xia. Y.

IPCC. (2014a). Climate Change 2014: Synthesis Report. Contribution of Working Groups I, II and III to the Fifth Assessment Report of the Intergovernmental Panel on Climate Change. Geneva, Switzerland: Pachauri, R. K., \& Meyer, L. A. Accessed 01/10/2018. Retrieved from https://www.ipcc.ch/report/ar5/syr/

IPCC. (2014b). Supplement to the 2006 IPCC Guidelines for National Greenhouse Gas Inventories - Wetlands. 
Karki, R. (2018). Vermi-biochar as alternative to peat as growing substrate for greenhouse vegetables. Retrieved from Brage - NMBU's Open Research Archive. https://brage.bibsys.no/xmlui/bitstream/ handle/11250/2502637/Karki.pdf?sequence=1\&isAllowed=y

Kern, J., Tammeorg, P., Shanskiy, M., Sakrabani, R., Knicker, H., Kammann, C., . . Glaser, B. (2017). Synergistic use of peat and charred material in growing media-An option to reduce the pressure on peatlands? Journal of Environmental Engineering and Landscape Management, 25, 160-174.

Lehmann, \& Joseph. (2015). Biochar for Environmental Management: Science, Technology and Implementation. Routledge.

Leng, L., Huang, H., Li, H., Li, J., \& Zhou, W. (2019). Biochar stability assessment methods: A review. Science of the Total Environment, 647, 210-222

Myers, R. (2011). Biochar as a Tool for Climate Change Mitigation and Soil Management, in Encyclopedia of Sustainability Science and Technology. R. Myers (Ed.). New York, NY: Springer. doi:10.1007/978-1-4419-0851-3

PBL Netherlands Environmental Assessment Agency. (2017). Limiting global temperature to $1.5^{\circ} \mathrm{C}$ (PBL publication number: 2743).

Paulis, R. (July 10, 2017). Peat and peat moss alternatives. Accessed 08/31/2018. Retrieved from https://www.gardenmyths.com/ peat-moss-alternatives/

Peano, L., Loerincik, Y., Margni,M., Rossi, V. Comparative life cycle assessment of horticultural growing media based on peat and other growing media constituents. Final report prepared by Quantis for the European Peat and Growing Media Association (EPAGMA), January 2012, Quantis Switzerland, Lausanne. Retrieved November 25th 2018 from comparative-life-cycle-assessment-of-horticultural-growing-media-based-on-peat-and-other-growing-media-constituents\%20(2).pdf

Saez de Bikuña Salinas, K., \& Ibrom, A. (2017). Enquiring into the roots of bioenergy - epistemic uncertainties in life cycle assessments. Accessed 09/07/2018. Retrieved from orbit.dtu.dk

Schmidt H-P., Anca-Couce, A., \& Hagemann N., Pyrogenic carbon capture and storage. GCB Bioenergy. https://doi.org/10.1111/ gcbb. 12553

Schmidt, J. H., \& Brandao, M. (2013). LCA Screening of Biofuels - Iluc, Biomass Manipulation and Soil Carbon. Copenhagen, Denmark.

Schmidt, J. H., Weidema, B. P., \& Brandão, M. (2015). A framework for modelling indirect land use changes in life cycle assessment. Journal of Cleaner Production, 99, 230-238
Spokas, K. (2010). Review of the stability of biochar in soils: predictability of 0:C molar ratios. Carbon Management, 1(2), 289-303.

Stadsbosbeheer, official Dutch website https://www.staatsbosbeheer. nl/over-staatsbosbeheer/dossiers/bos-en-hout/visie-en-beleid

Steiner, C., \& Harttung, T. (2014). Biochar as a growing media additive and peat substitute. Solid Earth, 5, 995.

The 75th Session of The UNECE Committee on Forests and Forest Industry. (2017). The Netherlands National Market Report 2017.

The Carbon Cycle Project. (2010). Global carbon cycle. Retrieved from http://kfrserver.natur.cuni.cz/globe/others.htm

The Eco Ferry Consortium (2013). Eco Island Ferry - Comparative LCA of island ferry with carbon fibre composite based and steel based structures. Aalborg, Denmark: Schmidt J. H., \& Watson, J.

Topsector Energie. (n.d.) EnerChar. Retrieved from https://projecten. topsectorenergie.nl/projecten/enerchar-00027462

UNFCC. (n.d.) National inventory submissions 2017. Accessed April 2018. Retrieved from http://unfccc.int/national_reports/annex_i_ ghg_inventories/national_inventories_submissions/items/10116. php

van Vuuren, D., Hof, A., Gernaat, D., de Boe H.-S. (2017). Limiting global temperature to $1.5^{\circ} \mathrm{C}$. Netherlands Environmental Assessment Agency (PBL), The Hague, 2017, PBL publishers. Publication number: 2743

Vaughn, S. F., Kenar, J. A., Eller, F. J., Moser, B. R., Jackson, M. A., \& Peterson, S.C. (2015). Physical and chemical characterization of biochars produced from coppiced wood of thirteen tree species for use in horticultural substrates. Industrial Crops and Products, $66,44-51$

Verhagen, A., van den Akker, J.J.H., Blok, C., Diemont, W.H., Joosten, J. H. J., M. A. Schouten, .. . Wösten, J. H. M. (2009). Scientific Assessment and Policy Analysis, the Netherlands Programme on Scientific Assessment and Policy Analysis Climate Change (WAB) Report nr. 500102 027, Peatlands and carbon flows, Outlook and importance for the Netherlands

Weidema B. P. (2009). Using the budget constraint to monetarise impact assessment results. Ecological Economics, 68(6),1591-1598.

Weidema, B. P., Wesnæs, M., Hermansen, J., Kristensen, T., Halberg, N. (2008). Environmental Improvement Potentials of Meat and Dairy Products. Eder P. \& Delgado L. (Eds.) Sevilla: Institute for Prospective Technological Studies.

Woolf, D., Amonette, J. E., Street-Perrott, F. A., Lehmann, J., \& Joseph, S. (2010). Sustainable biochar to mitigate global climate change. Nature Communications, 1,56. 